\title{
Geomorphological Challenges of Systematic Attitude
}

\section{A R T I C L E I N F O}

\section{Article Type}

Original Research

\section{Authors}

Jafari Gh. ${ }^{* 1} P h D$
How to cite this article

Jafari Gh. Geomorphological Challenges of Systematic Attitude. Geographical Researches Quarterly Journal. 2019;34(2):245-255.
*Department of Geography, Faculty of Humanities, University of Zanjan, Zanjan, Iran

\section{*Correspondence}

Address: No. 605, Department of Geography, Faculty of Humanities, University of Zanjan, Kilometer 5 of Zanjan-Tabriz Old Road, Zanjan, Iran Phone: +98 (24) 33054176 Fax: +98 (24) 33052299 jafarihas@znu.ac.ir

\section{Article History}

Received: January 9, 2018

Accepted: March 16, 2019

ePublished: June 20, 2019

\section{A B S T R A C T}

Aims \& Backgrounds Understanding the geomorphological issues depend on the type of researcher's perspective. The habit of today is that what is seen can be taken as a whole and treated as a system. However, what is considered as a whole and a system is only a part of a complex system and it has played a role in landform evolution and even if it considered as a hole, it lacks of environmental body. This study aimed to investigate the geomorphological challenges of systematic attitude.

Methodology The methodology of this research was based on the analysis and explanation. With this approach, first, through the knowledge of available research on geomorphological systems and the strengths and weaknesses of the results of a systematic approach in geomorphology studies, the available resources in relation to science and philosophy of science were investigated and they were analyzed from the modernity to postmodernity era. Discussions on space analysis, especially in geography, were reviewed. Finally, the combination of findings from the above sources was analyzed and explained considering the geomorphological studies in Iran over the last few decades.

Findings The necessary condition to be beneficial of scientific research for human society is revealing a small part of the real world unknowns. It is true that human knowledge is always incomplete and imperfect and remains incomplete and as the point of human life has been revealed, the background to the emergence of many unknowns has been provided; but in the light of the same incomplete sciences, human has succeeded in inventing and constructing a lot of things that have made life more accessible. Usually, phenomena occur in geomorphic domains and they are appearing in geomorphologic basins. Conclusion The best way to understand the general geomorphic events is to select the number of separate geomorphologic landscapes that operate on a certain part of the planet and put them together in order to examine the effectiveness of their obvious and hidden layers in the development of landforms in a comprehensive and precise manner.

Keywords System; Phenomenology; Dasein; Natural Hazards; Geomorphology

\section{I T A T I O N L I N K S}

[Afraketh; 2016] The transformation ...; [Ahmadi \& Alijani; 2007] Spatial ...; [Ajili \& Solgi; 2016] Critique of ...; [Alijani; 2015] Spatial analysis ...; [Alijani \& Babaie-Fini; 2009] Spatial ...; [Asakereh \& Shadman; 2015] Recognition of ...; [Baas; 2007] Complex ...; [Bahak; 2018] Spatial analysis ...; [Behyar \& Pishdad; 2016] Spatial analysis ...; [Dehbashi \& Ayatollahi; 2009] Husserl's ...; [Dermot; 2000] Introduction to ...; [Emami Sigaroodi, et al; 2012] Qualitative ...; [Fattahian; 2013] Changes in ...; [Ghaiumi Mohammadi, et al; 2009] Space and spatial ...; [Glenn Carrey; 2011] Being and human ...; [Habibi; 2008] Introduction to the ...; [Harary; 2015] Sapiens, human ...; [Heidegger; 2017] Being and ...; [Hidari; 2007] The Da« (da) on “Dasein» ...; [Hidarifar; 2013] Globalization and ...; [Jahani; 2005] Chaos in ...; [Jamali, et al; 2015] Spatial analysis ...; [Kavianirad; 2011] Assessment ...; [Keller \& Pinter; 2001] Active ...; [Khanjar-Khani, et al; 2010] Types of interdisciplinary ...; [Lashgari-Tafreshi; 2016] Inquiry to ...; [Lshgari-Tafreshi \& Ahmadi; 2017] Principles ...; [Masoudi; 2013] Hermeneutics ...; [MirHeidar \& Hamidinia; 2006] Methodology ...; [Mir-Mosavi, et al; 2016] Analyzing ...; [Moosavi, et al; 2018] Spatial analysis ...; [Nawali; 1990] What is ...; [Nietzsche; 1993] The will to ...; [Olverflet; 2015] System theory in ...; [Parizadi \& Salehi; 2018] Spatial ...; [Partovi;2016] Phenomenology ...; [Ramesht, et al; 2016] Evolutionary in...; [Ramesht;2011] Space in ...; [Ramesht, et al; 2016] Space identity ...; [Ramesht, et al; 2017] Relativism in ...; [Rosen; 2002] Are there ...; [Rummel; 1997] Death by ...; [Sadeghi \& Shokryani; 2016] Spatial analysis ...; [Sadeghinia, et al; 2013] Analysis of ...; [Salimi-Bajestani \& Vojdani-Hemmat; 2015] A comparative ...; [Shamaei, et al; 2016] Spatial ...; [Shayan, et al; 2016] Spatial ...; [Shayan, et al; 2011] Spatial analyses ...; [Sheykh Beygloo, et al; 2012] The spatial ...; [Shokouie; 2016] New thoughts ...; [Sohrabifar; 2017] Heidegger and ...; [Taghvaei \& Kiumarsi; 2013] Spatial analysis ...; [VanManen;2018] Researching lived ...; [Yousofi \& Tabei; 2012] Empirical ...; [Babaie \& Alijani; 2013] Spatial analysis ...; [Davari-Ardakani; 2007] About science; [Hatami-Nezhad; 2012] Radical ...; [Ahmadi; 2016] Spatial analysis ...; [Vasegh, et al; 2016] Political geography ... 
مراجعه كنيم و اجازه دهيم تا او، آنَّنه كه است، بر ما ظهور و

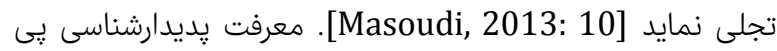
بردن به ساختار اساسى يديدهها و كشف معناي نهائ نهفته آنها است

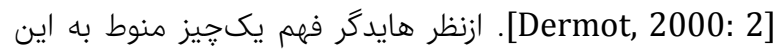

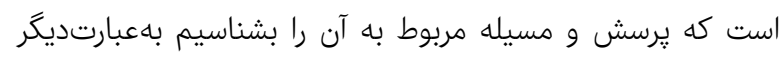

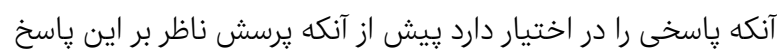

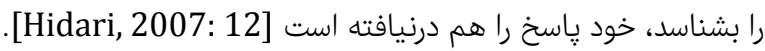

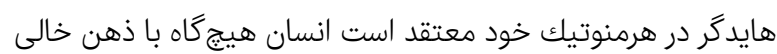

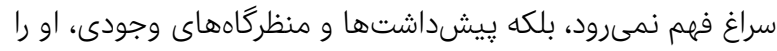
در هر فهمى همراهى مى كنند و فهم انسان مسبوق به به ساختارى

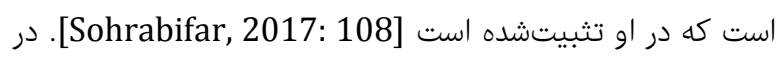
اصطلاحشناسى كتاب هستى و زمان، برسنده موجودى است كه بـ به

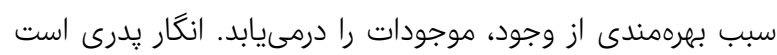

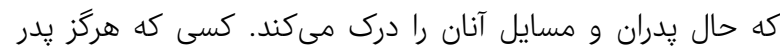

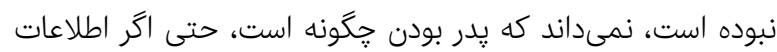

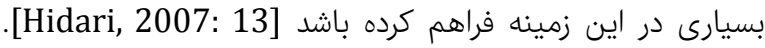

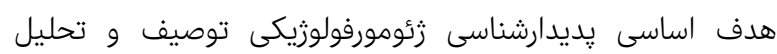

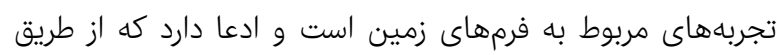

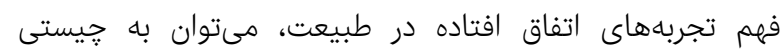

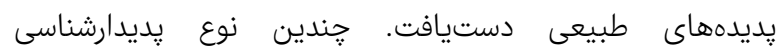

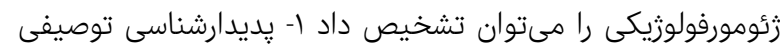

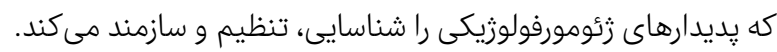

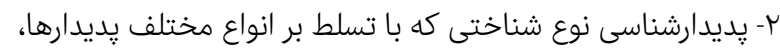

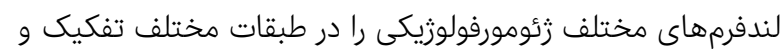

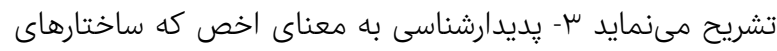

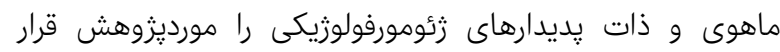

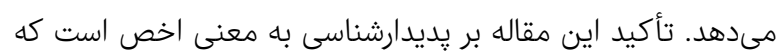
بر فهم تجربههاى زئومورفولوزيكى استوار است.

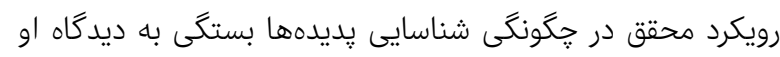

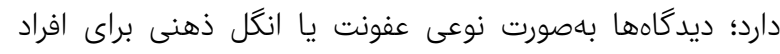

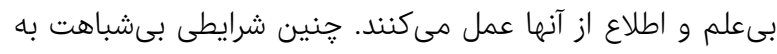

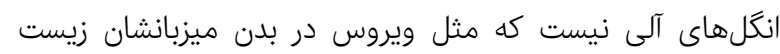

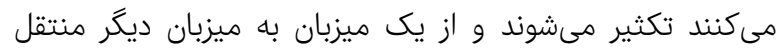

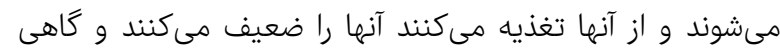

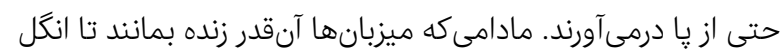

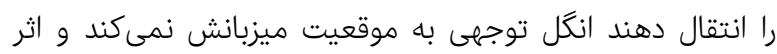

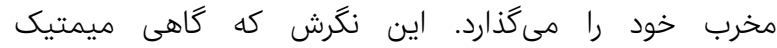
خوانده مىشود، درست همانند تكامل موجود زنده الندان

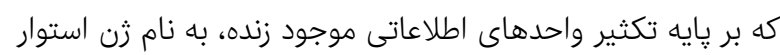

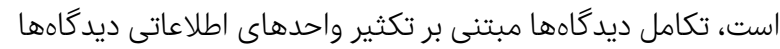

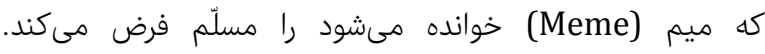
ديدكاههاى موفق آنهايى هستند كه عليرغم نفع و زيان انسان انسانهاى

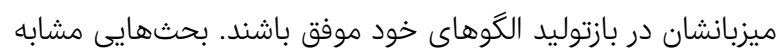
اينها در علوم اجتماعى تحت يوشش نظريه بازى رواج دارد. نظريه

\section{جالشهاى زئومورفولوزيستى نكرش سيستمى}

PhD *

گَروه جغرافيا، دانشكده علوم انسانى، دانشگَاه زنجان، زنجان، ايران

جكيده

اهداف و زمينهها: درى مسايل زئومورفولوزيك، بهشدت به نوع ديدگاه محقق

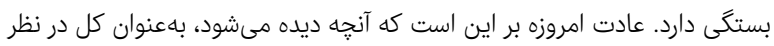

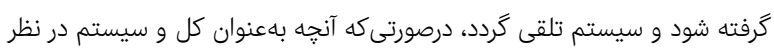

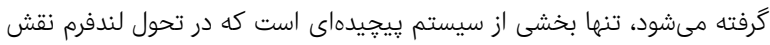

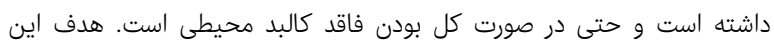
مطالعه بررسى جالشهاى ثئومورفولوزيستى نكرش سيستمى دور بود.

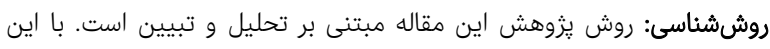

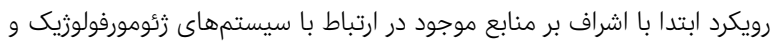

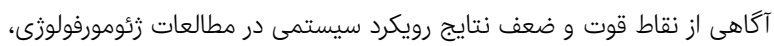
منابع موجود در ارتباط با علم و فلسفه علم بررسى و در ارتباط با تحول علم از از

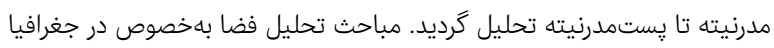

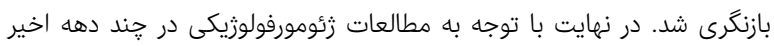

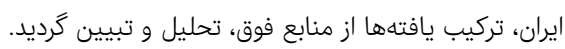

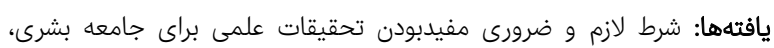

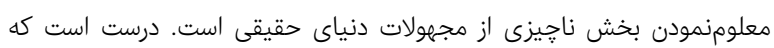

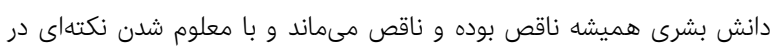

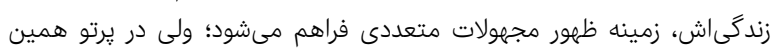

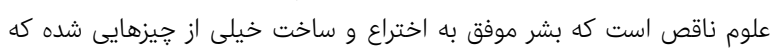

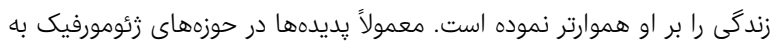

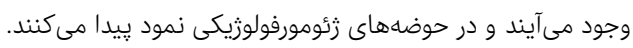
نتيجه

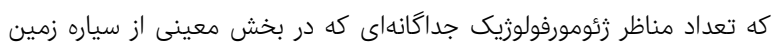

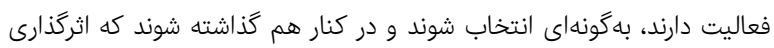

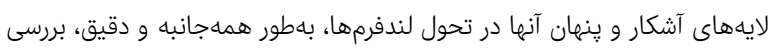

شود.

كليدوارهها: سيستم، پِديدارشناسى، دازاين، مخاطرات طبيعى، زئومورفولوزى

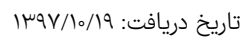

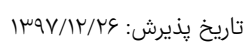
خويسنده مسئول: jafarihas@znu.ac.ir

مقدمه

علم، نظامى بناشده بر واقعيتهاست [Habibi, 2008:5] و مجانش

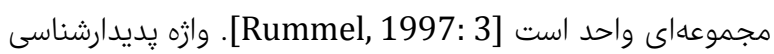
به لحاظ لغوى به شناخت يديدهها از طريق تحليل آنها اطلاق مى إشود [Dehbashi \& Ayatollahi, 2009: 2]

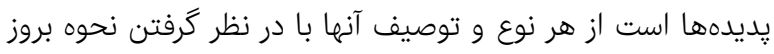

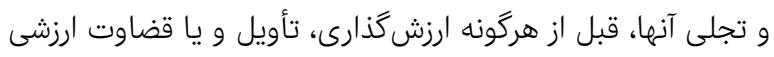

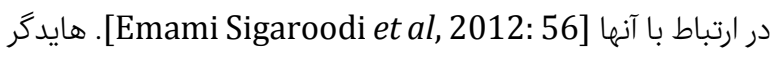

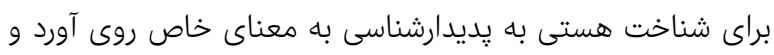

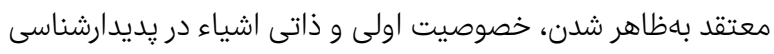

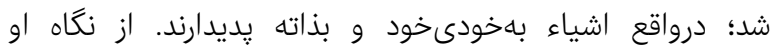

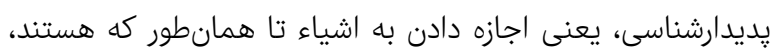
خود را آشكار كنند و ما براى فهم هستى لازم است، مرفاً به او او بله 
سيستمهاى زمينى است. جزئى كردن عناصر و عوامل مؤثر در ايجاد

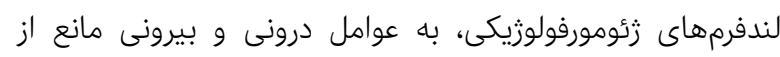

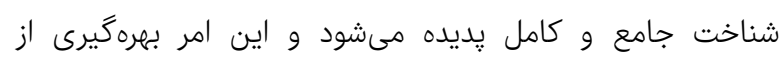

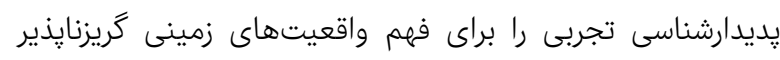

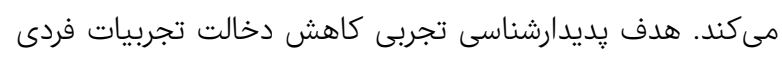

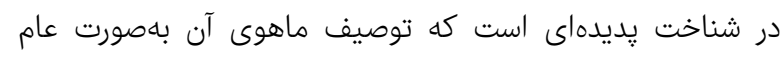

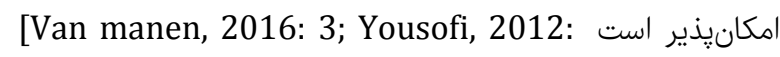

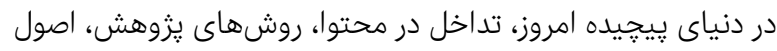

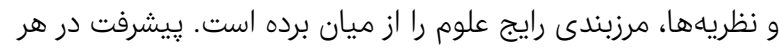

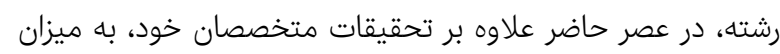

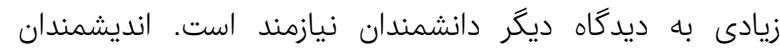

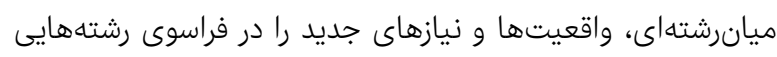

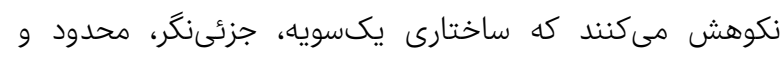

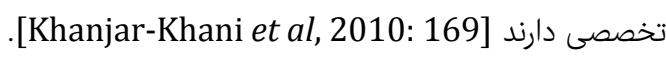

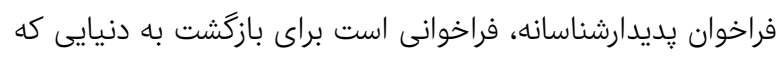

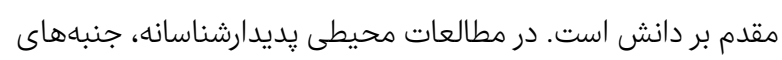

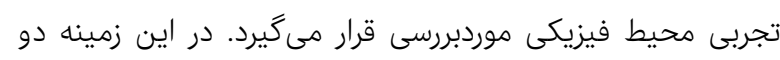

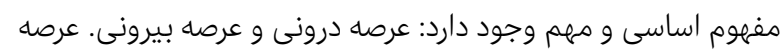

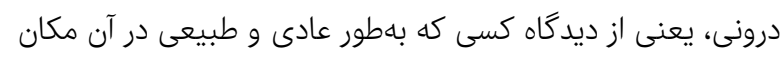

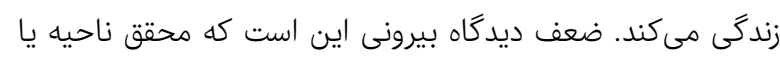

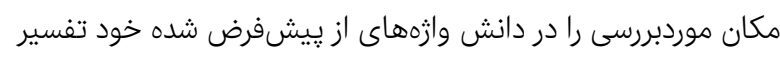

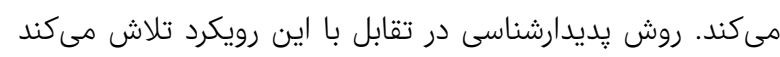

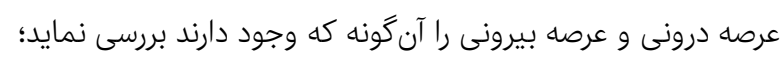

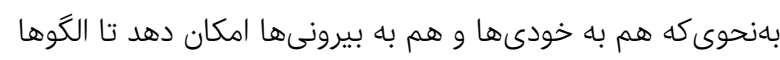

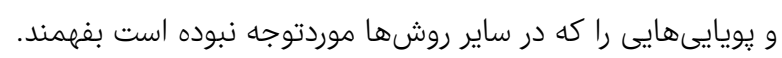

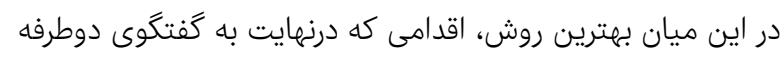

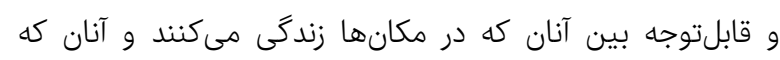

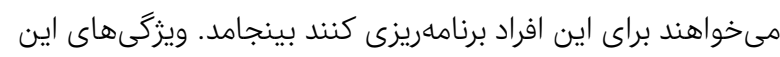

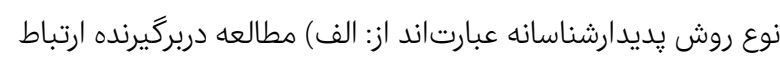

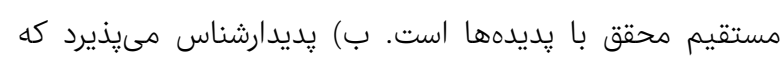

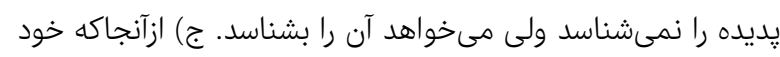

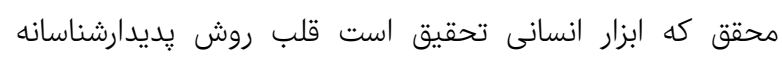

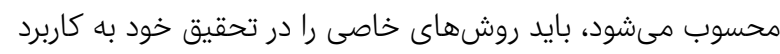

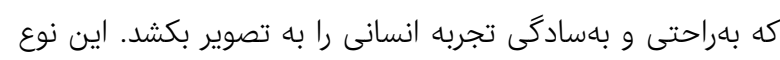

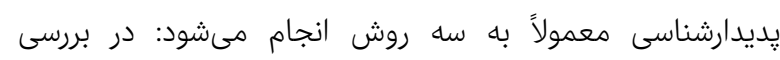

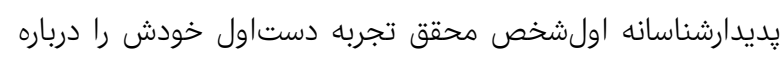

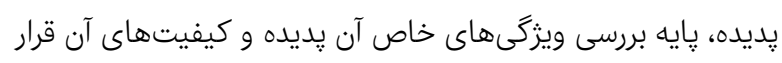

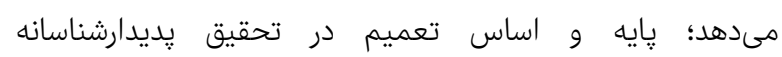

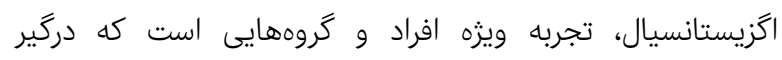

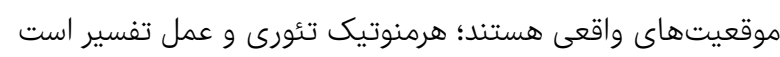

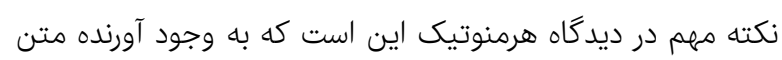

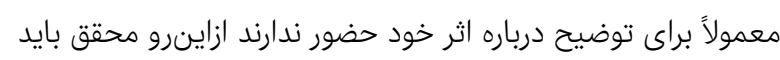

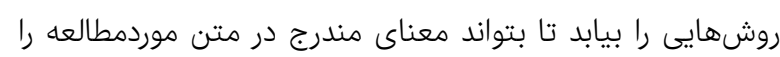

بازى توضيح مى فهد كه در نظامى با هندين بازيكر، هَكونه الكَوى

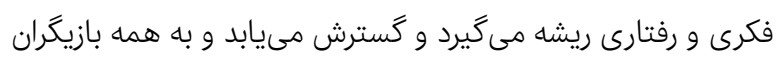

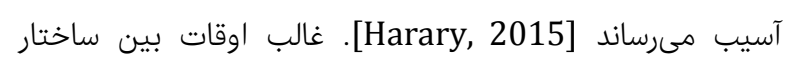
(Agent) و (Atructure)

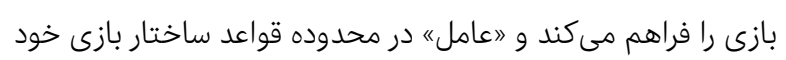

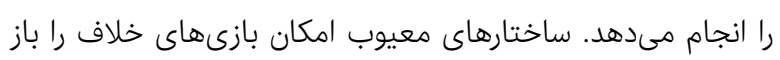

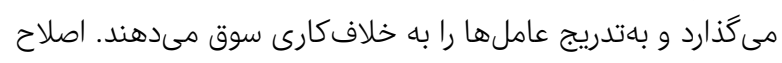

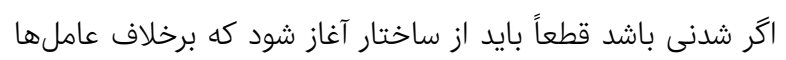
كنترليذير و عينى است.

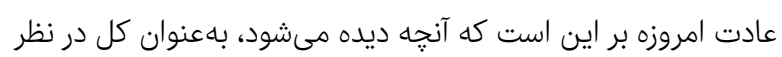

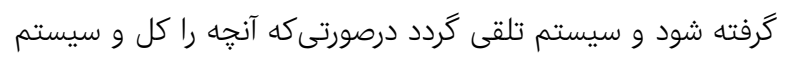

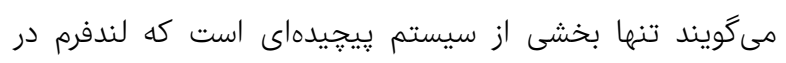

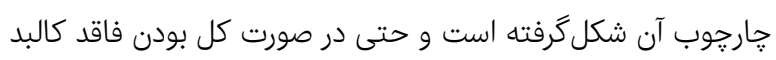

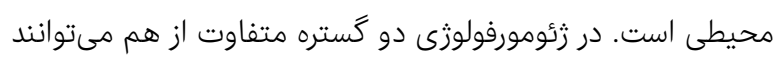

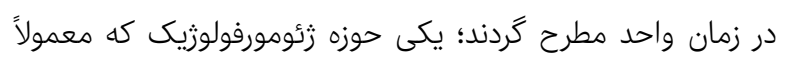

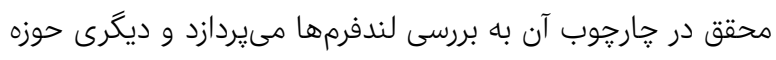

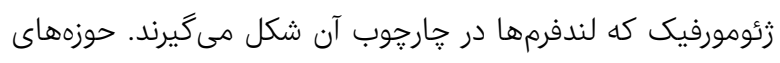

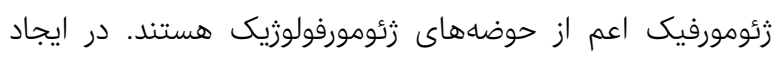

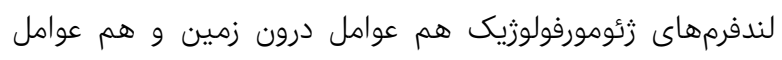

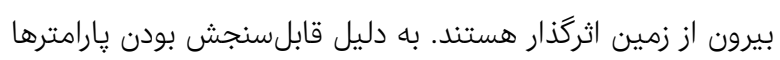

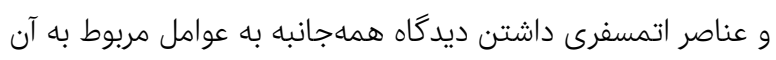

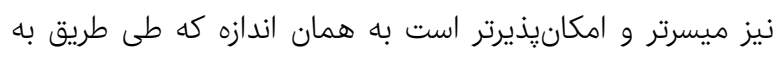

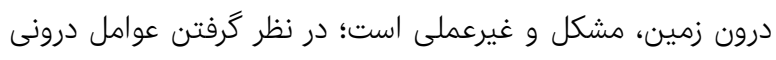

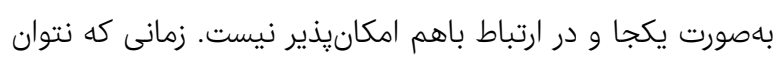

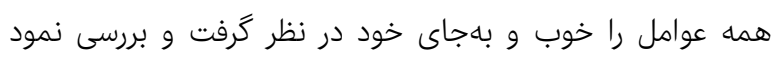

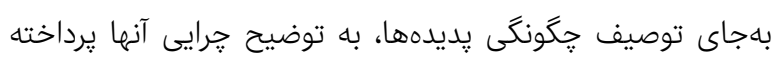

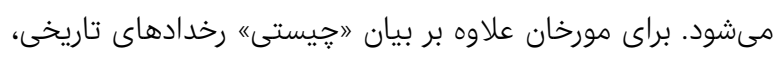

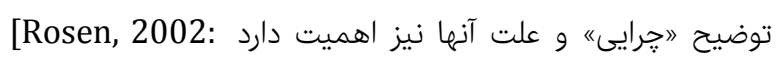

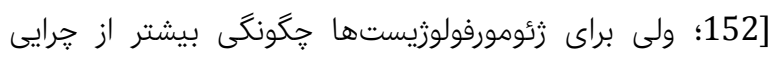

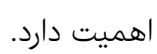

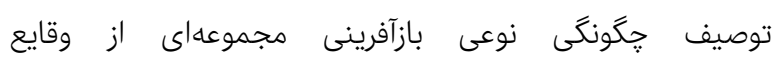

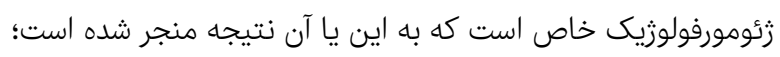

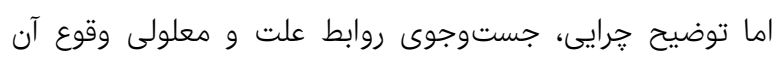

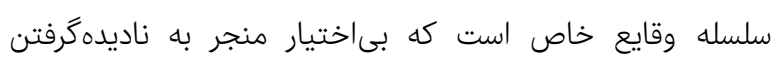

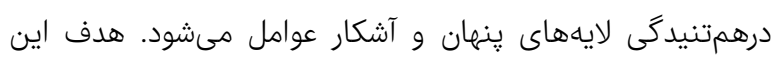

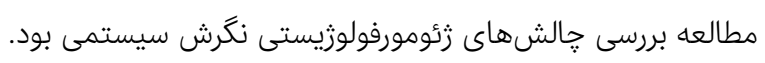

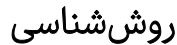

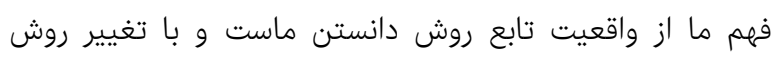

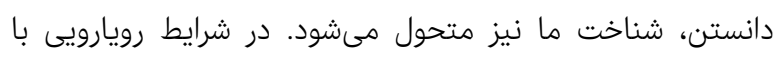

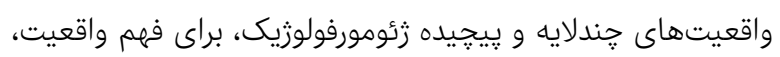

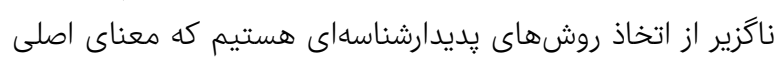

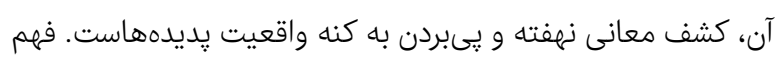

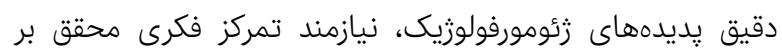


مىكند و عامل متناسب با اجتماع خود، طراح مىشود. تمام تلاش

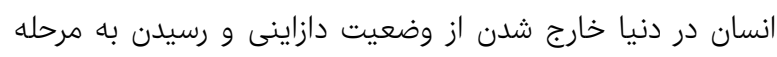

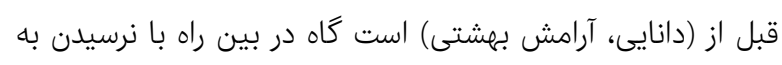

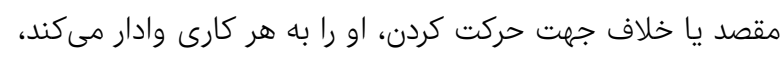

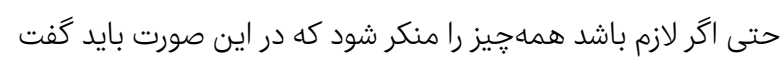

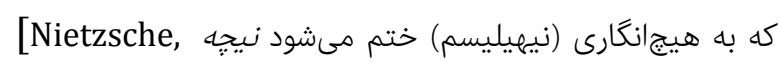
[1993 هيجانكارى را "احد نهايى اعتراف به اتلاف مزمن نيروهاى نيجاى

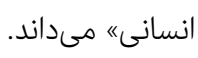

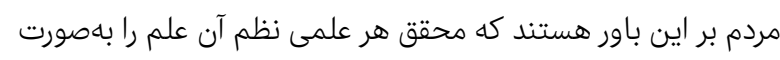

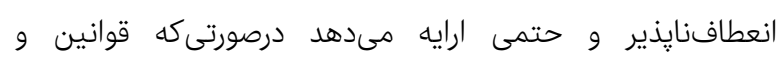

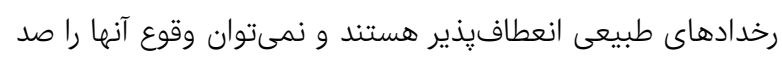

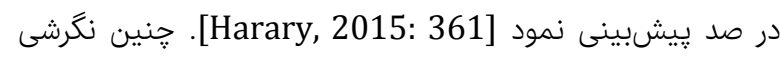

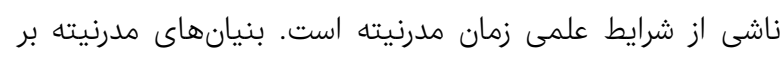

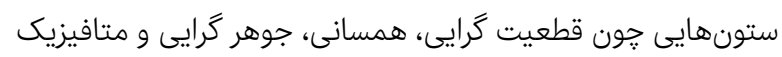

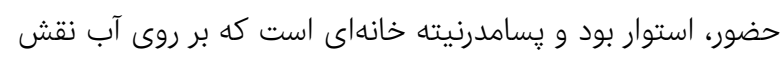

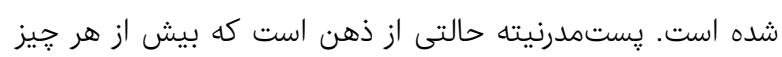

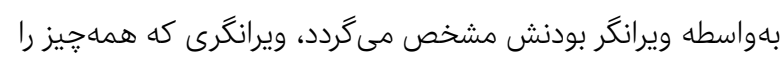

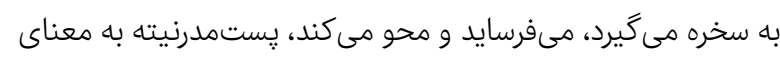

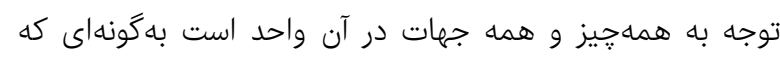

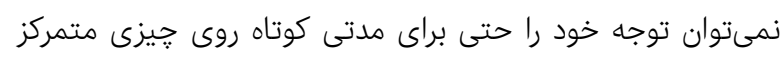

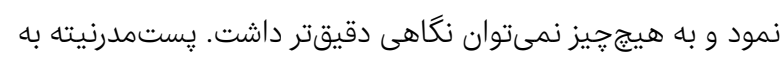

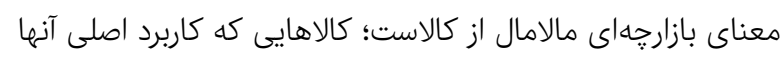

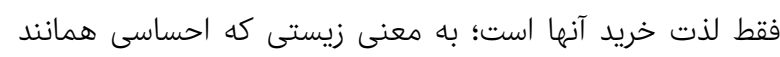

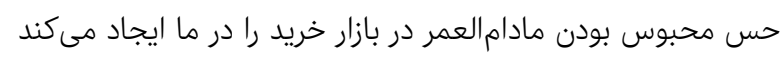

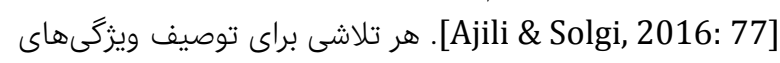

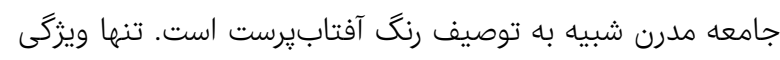
حتمى، تغيير مداوم است [Harary, 2015:498]

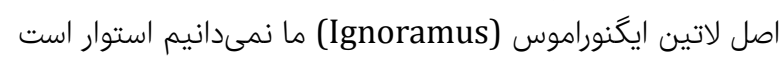

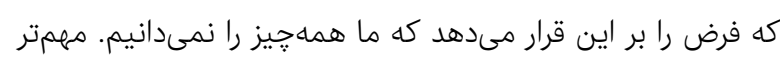

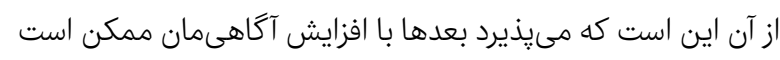

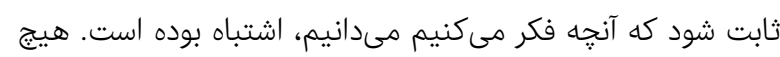

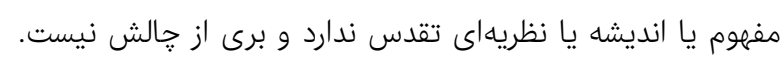

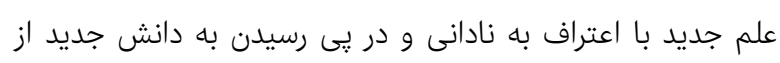

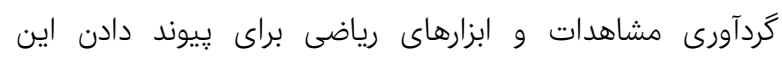

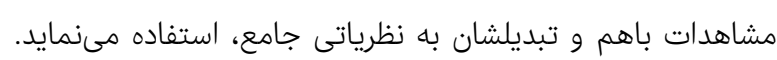

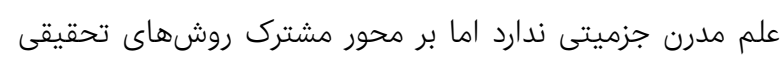

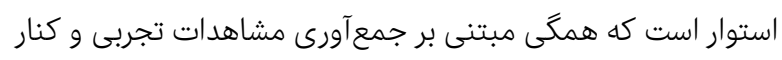

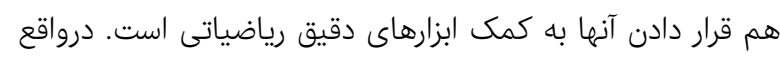

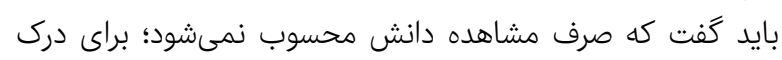

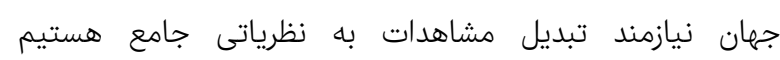

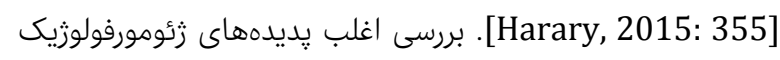

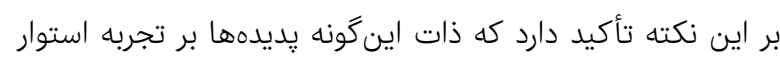

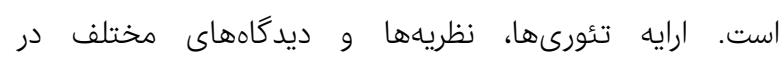

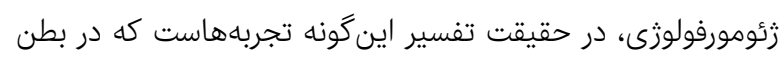

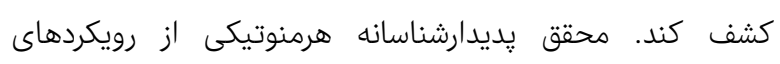

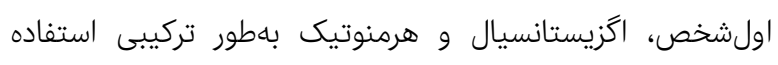

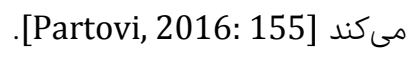

روش اين مقاله مبتنى بر تحليل و تبييين است. ازاينرو ابتدا با

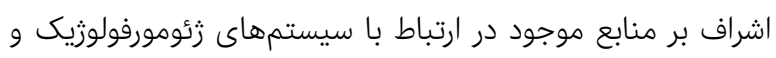

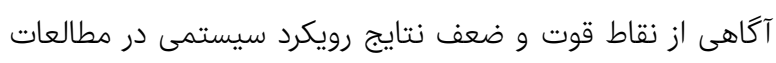

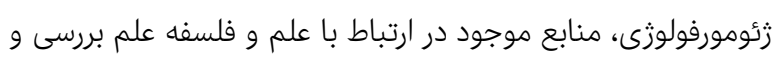

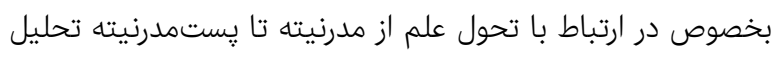

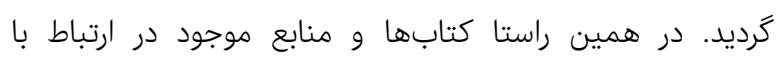

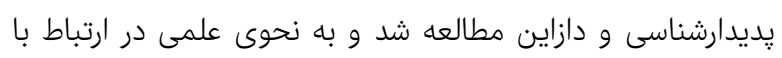

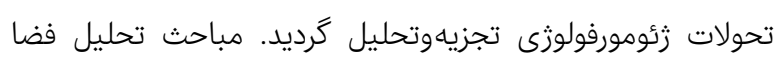

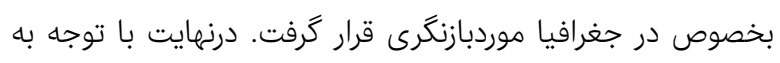

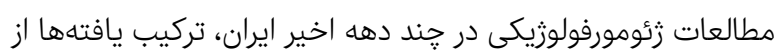
منابع فوق، تحليل و تبيين كَرديد.

\section{يافتهها}

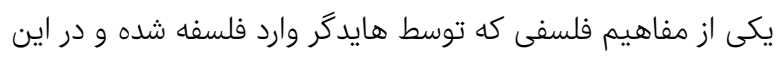

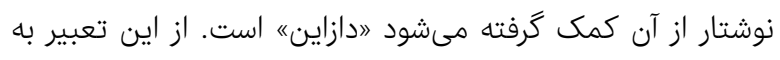

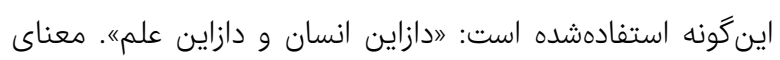

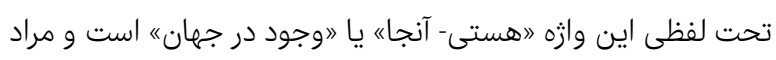

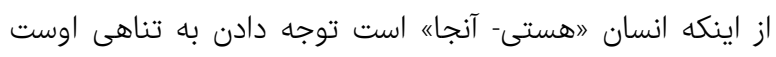

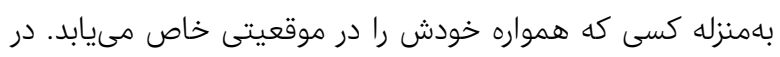

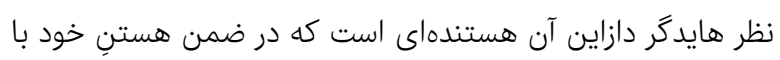

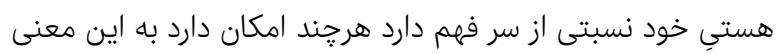

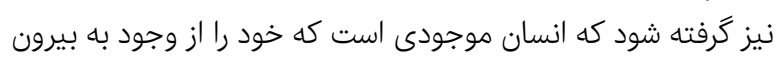

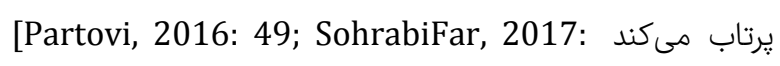

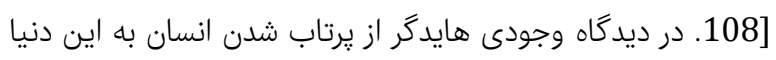

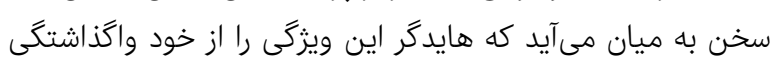

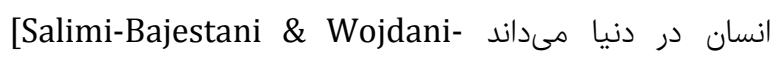

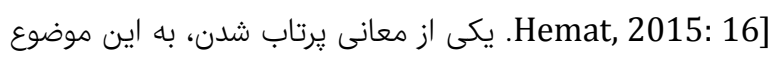

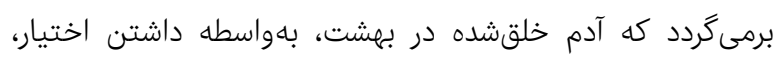

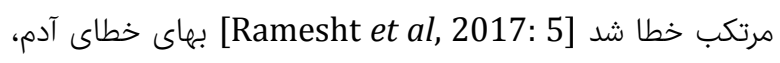

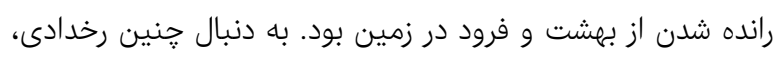

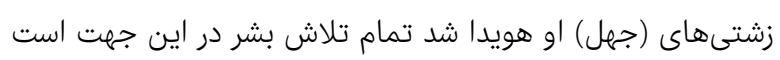

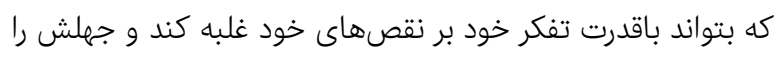

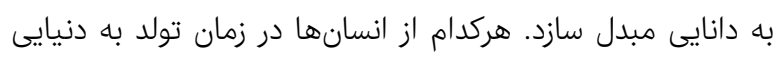

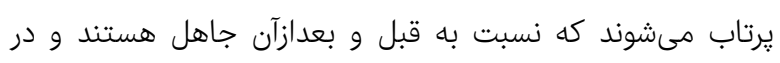

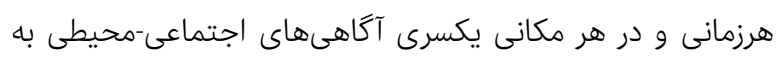

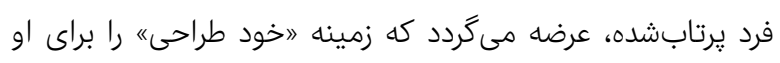

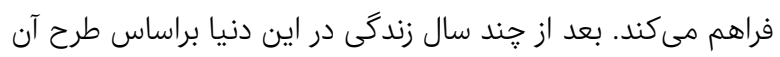

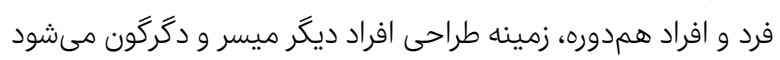

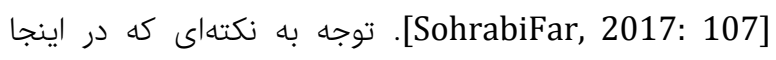

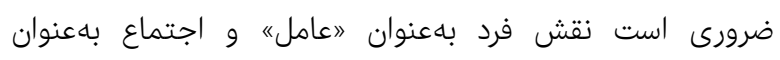

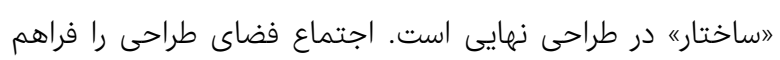


نمىتوان در مورد اثرگذارى واقعى آنها اظهارنظر دقيقى كرد. جهابسا

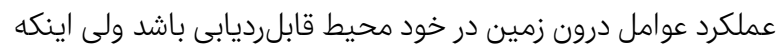

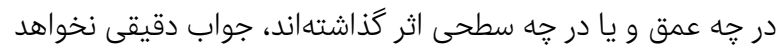

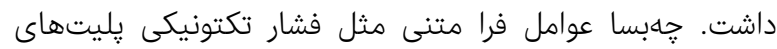

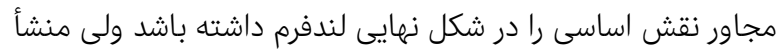
دقيق آنها را نمىتوان تعيين نمود. حال در نظرگيريد كه سازوكارهاى

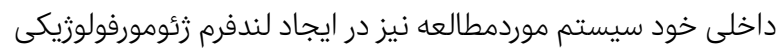

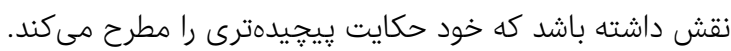
در بسيارى از موارد زئومورفولوزيستها همانند هيدرولوزيستها، حوضه هيدرولوزيكى را طبيعىترين مرز مطالعاتى خود قرو قلمداد

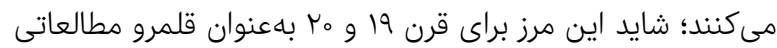

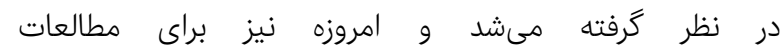
هيدروزئومورفولوزيكى هنوز هم باعنوان مرز مطالعاتى در نظر كرفته مرفيه

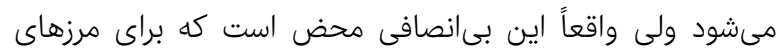

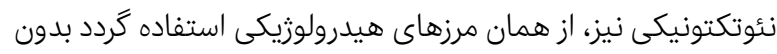

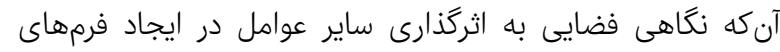

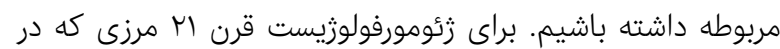
مطالعات زئومورفولوزى اهميت دارد "امرز حوضه زئومورفولوزيكى و

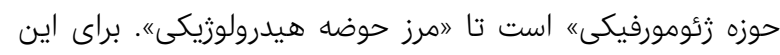

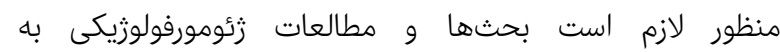
سمتوسويى هدايت شود كه نهتنها بتواند نقش همه عوامل درونى مهات

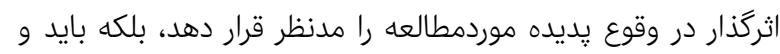

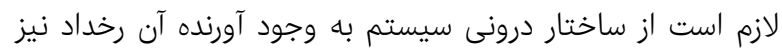
آكًاهى كامل و كافى داشته باشد تا بتواند خروجى سيستم إنى (فرم

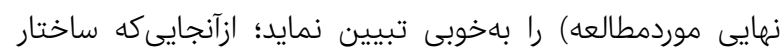

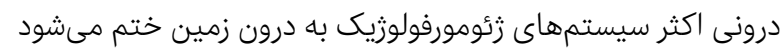

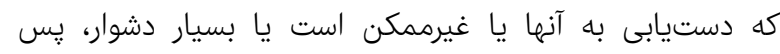

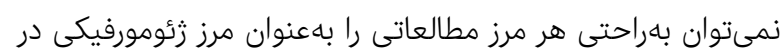

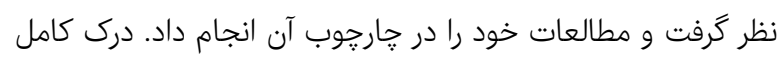

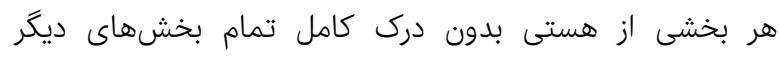

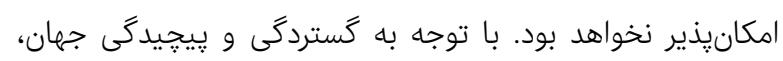

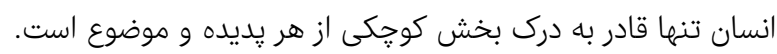

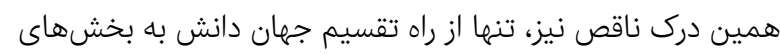

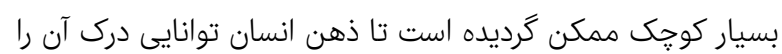

داشته باشد [Mir-heidar \& Hamidinia, 2006: 2] در نظر كرفتن بخشهاى كوجى جهان باعنوان سيستمهاى مجزا

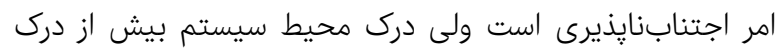
اجزاى آن اهميت دارد درصورتى كه كمتر موردتوجه قرارگرفته است. زئومورفولوزيست تمركز خود را از محيط سيستم (حوزه زئومورفيك)،

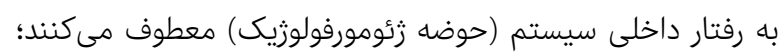

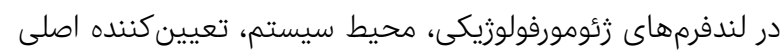
رفتار سيستم است كه در تحقيقات به فراموشى سيردهشده استئ. جنين رويكردى در مسايل زئومورفولوزى همجيون كودكى مى دماند

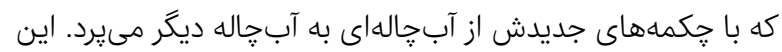

محيط اتفاق افتاده يا اتفاق مىافتد. رخدادهاى زئومورفولوزيكى

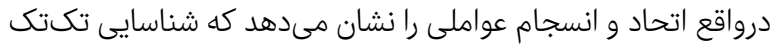

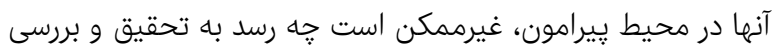

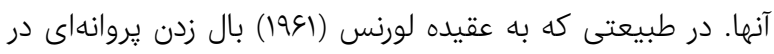

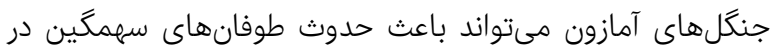
آمريكاى شمالى شود [Fatahiyan, 2013:

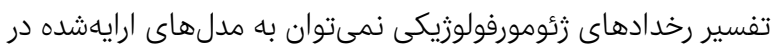

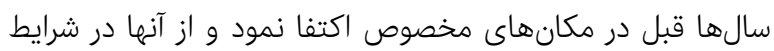

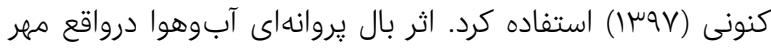

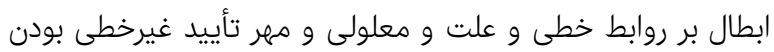

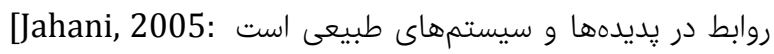

لازمه نظريهيردازى در علم مدرن تحليل فضايى يديدهایى موردمطالعه است. تحليل فضايى در گرايشهاى ديكر جغرافيا بيشتر

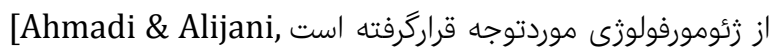
2007; Alijani \& Babaie-Fini, 2009; Ghaiumi Mohammadi et al, 2009; Sheykh Beygloo et al, 2012; Sadeghinia et al, 2013; Taghvaei \& Kiumarsi, 2013; Alijani, 2015; Shamaei et al, 2016; Behyar \& Pishdad, 2016; Mir-Mosavi et al, 2016; Sadeghi \& Shokryani, 2016; Parizadi \& Salehi, 2018; Moosavi et al,2017; Asakereh \& Shadman, 2015; Bahak, [2018 نكرش فضايى بهطور خاص در زئومورفولوزى ايران با مقاله

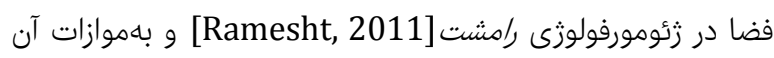
در مطالعات خاك و زئومورفولوزى باهواسطه يكى از دانشجويان

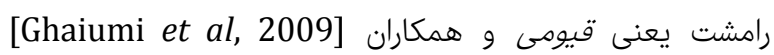

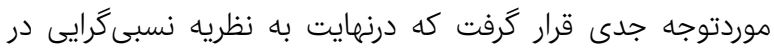
زئومورفولوزى رامشت و همكاران [Ramesht et al, 2017] ختم

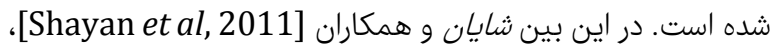
جمالى و همكاران [Jamali et al, 2015] شايان و همكاران [Ramesht, 2015] [Shayan et al, 2016] به ترتيب در تحليل مخاطره زئومورفولوزيكى شورى زايى در

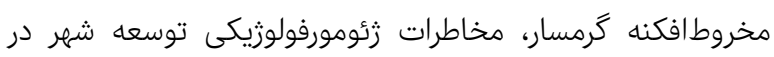

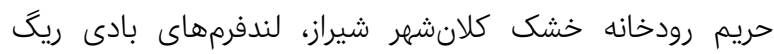
اردستان و تبلور هسته مدنى ايران از تحليل فضايى استفاده كردهاند.

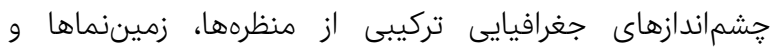

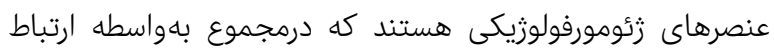

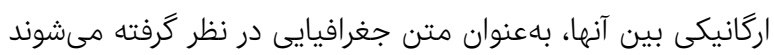

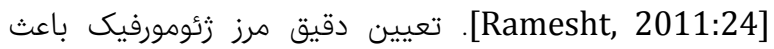
مىشود كه نهتنها نقش عوامل درونمتنى، بلكه نقش عوامل فرا

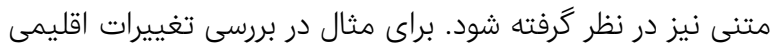

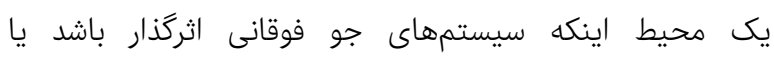

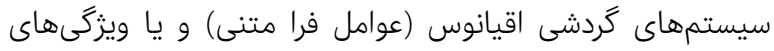

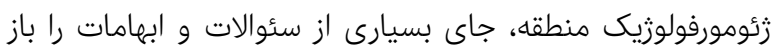

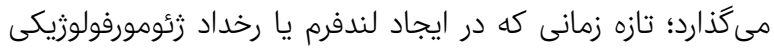

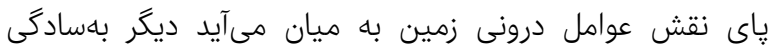


اينجاست كه محقق از شناخت و تفكيك آن قسمت از يهنه از ساير قسمتهاى همشيب، عاجز مىماند. وجود رجنين إنين ساختارهاى

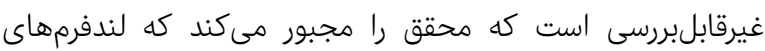

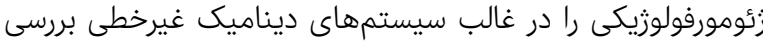

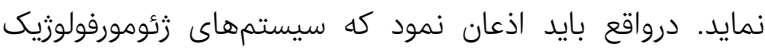
سيستمهاى يبيجيدهاى هستند كه در آنها هميشه علت، علت نيست

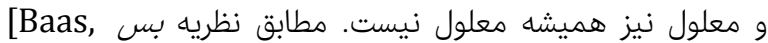
[ 2007: 340 اين سيستم بلهوسيله سه خله خصيصه اصلى نئل

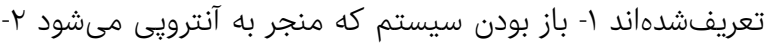

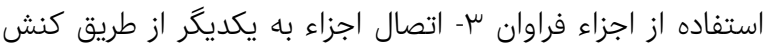

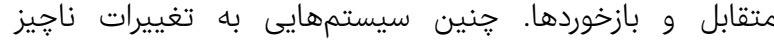

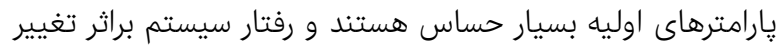

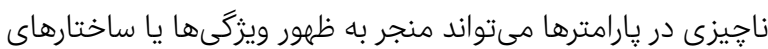

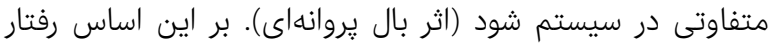

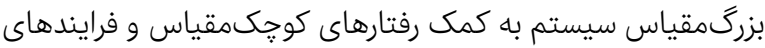

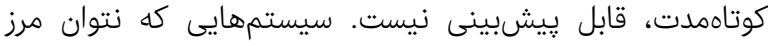

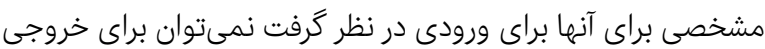

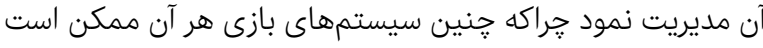

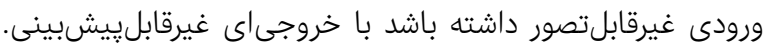

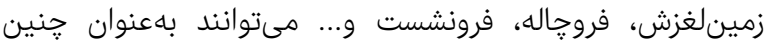

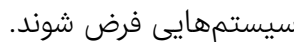

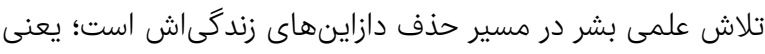

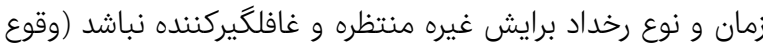

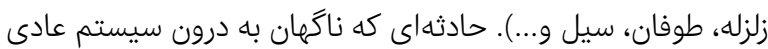

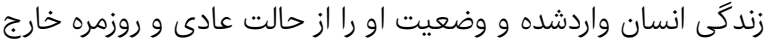

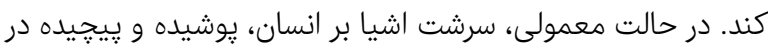

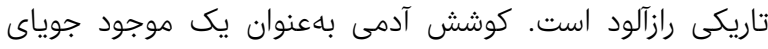

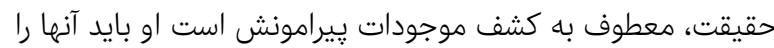
جنانكه براى او هستند، بشناسد؛ اما اين كار بسى دشوار برار است؛

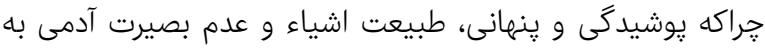

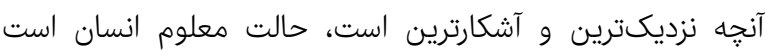
[Glenn Carrey, 2011: 110] هايدكر سرسختانه معتقد است است كه هستى رازآلود نيست كه فهم آن محتاج توانايىهاى خاص خاص باشد،

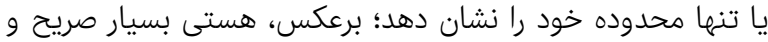

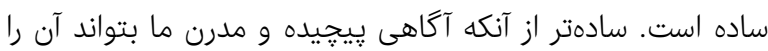

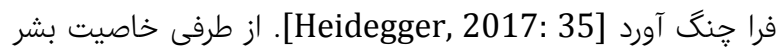
يِيجيده كردن وظيفهاش در مقابل كشف حقايق است. متخصصان

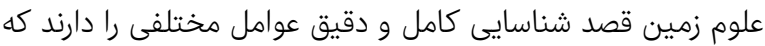

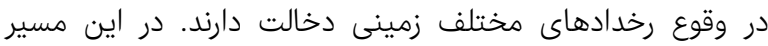

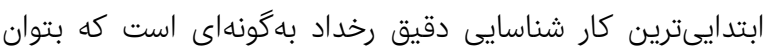
ورودىها و دروندادهاى مؤثر بر خروجى (رخداد) را دقيق شناسين استاسيى

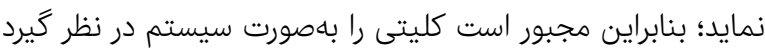

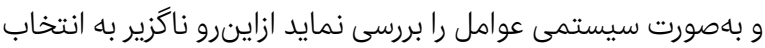
مرز است. در اين ميان معمولاً بين آنجه مرز واقعى رخدادهاى
نكَرش زمين را عرصه جهشهايى مىداند ير از رخدادهاى مختلف و

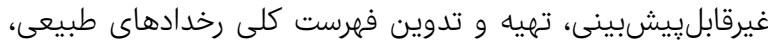

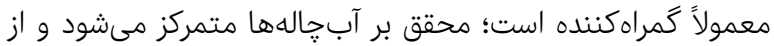

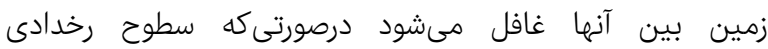
(آبجالهها) و غير رخدادى (سطوح بين آنها) در ارتباط متقابل باهم

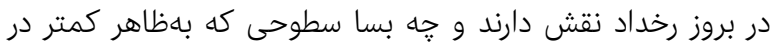

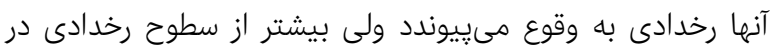

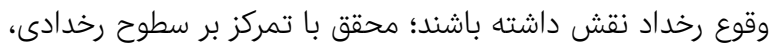

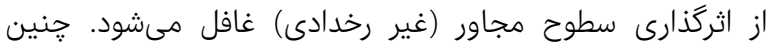
مسايلى دال بر انتخاب نادرست مرز سيستم در بسيارى از مطالعالعات زئومورفولوزيكى است كه باعث عقيم شدن نتايج در حل مسايل [Olverflet, روزمره شده است. از اين نظر مطابق عقيده الورفلت

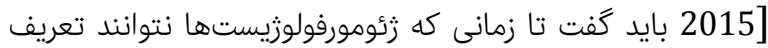

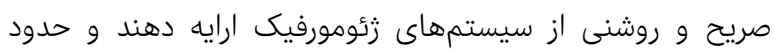

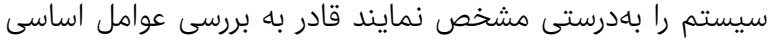

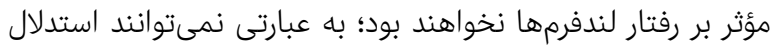

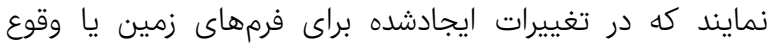

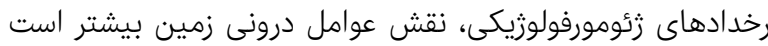

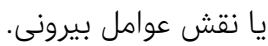
بررسى عوامل مجهول الهويه در تحليل لندفرم زئومورفولوزيك واحد

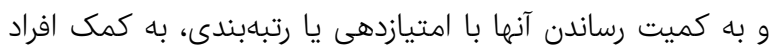

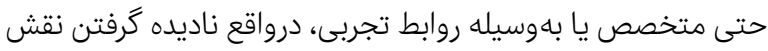

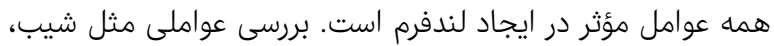

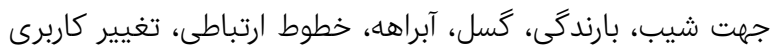

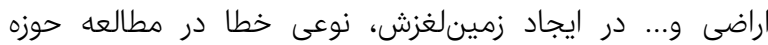

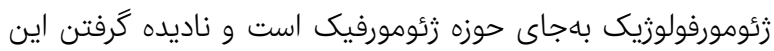

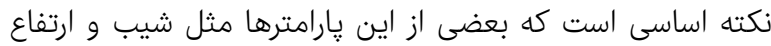

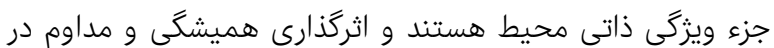

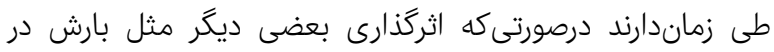

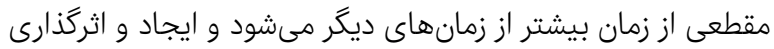

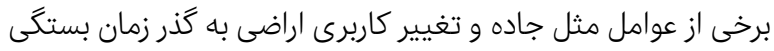

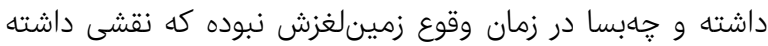

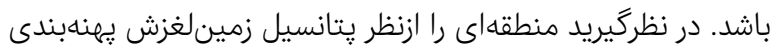

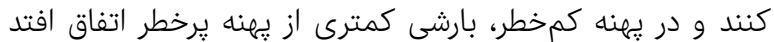

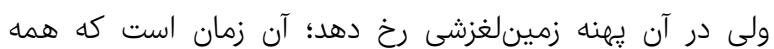

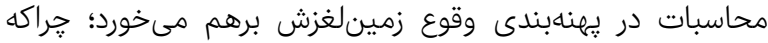

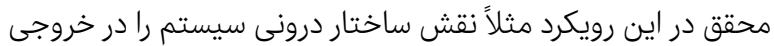

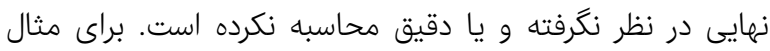

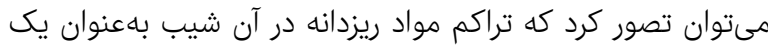

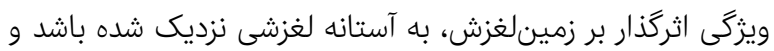

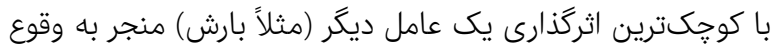

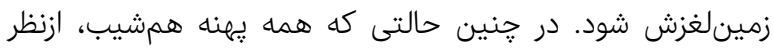

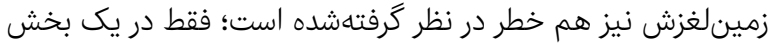

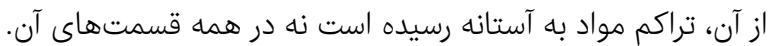




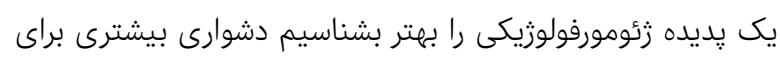

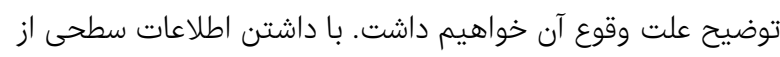

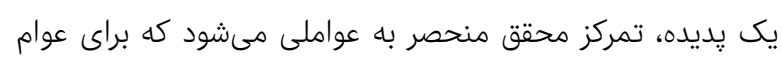

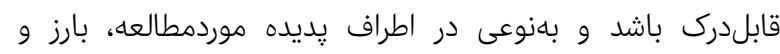

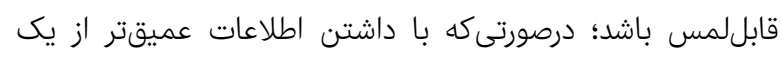

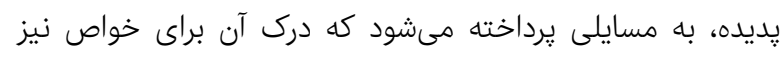

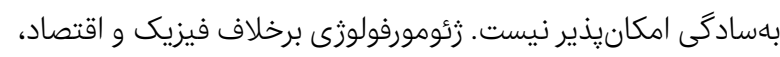

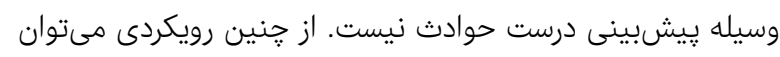

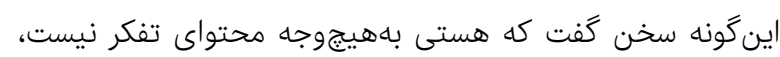

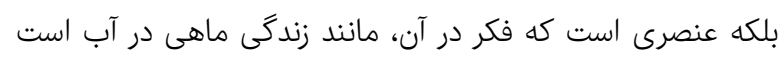

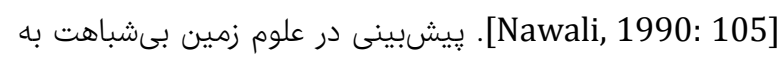

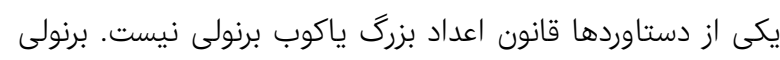

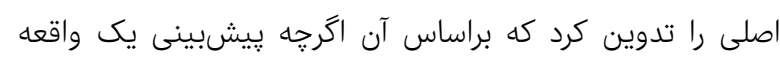

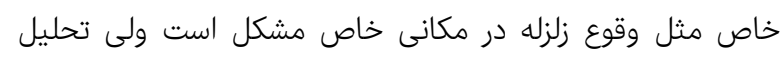

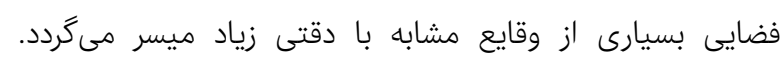

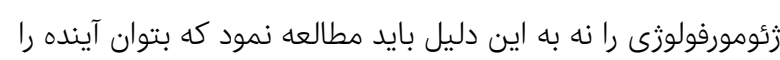

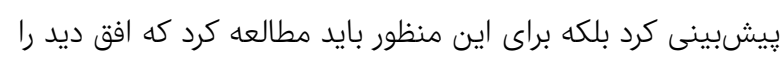

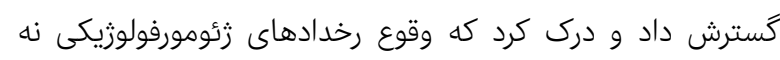

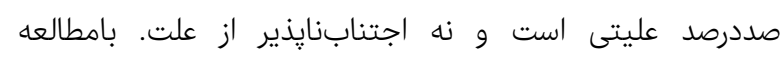

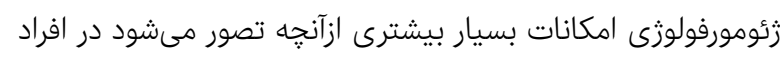

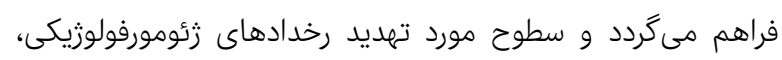
بهتر شناخته مىشوند و با استعانت از ساير علوم تداركات محيطى رئى

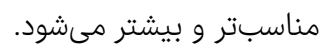

بحث

حال بايد ديد اگر فرد زئومورفولوزيست يتانسيل لازم براى تسلط

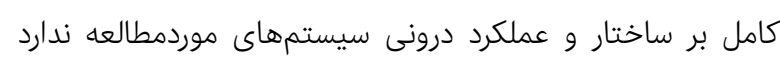

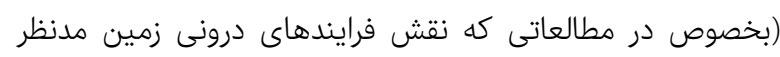

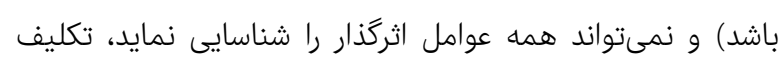

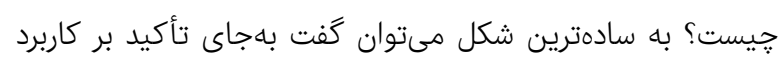

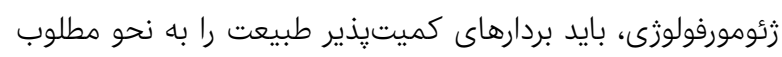

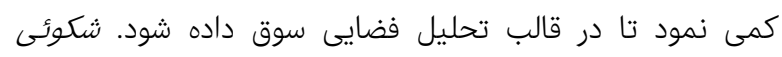

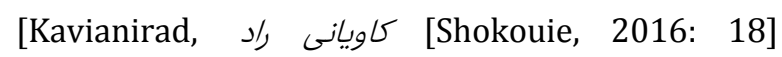
[Lshgari-Tafreshi \& 2011:84] [Lshgari-Tafreshi, و لشكرى تفرى لشفى Ahmadi; 2017]

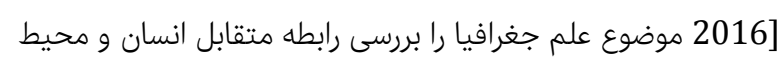

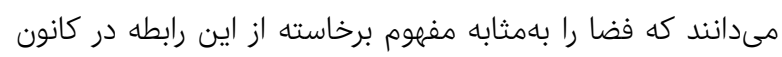

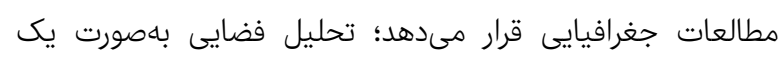

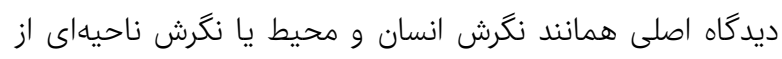

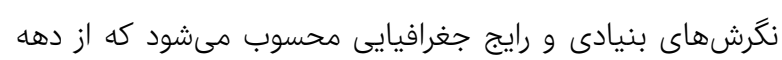

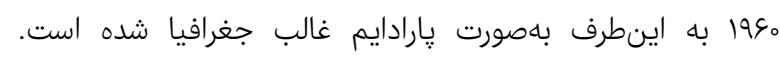

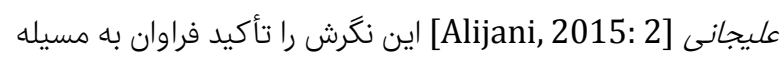

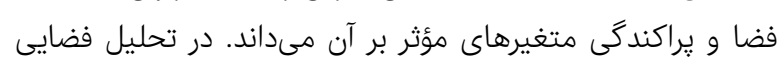

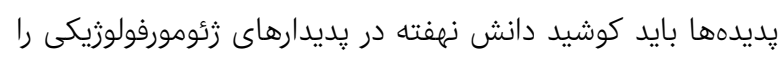

طبيعى است و آنجه محقق آن را مرز مى يندارد، تفاوت حادى وجود

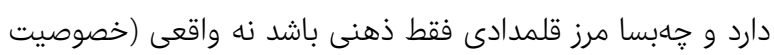

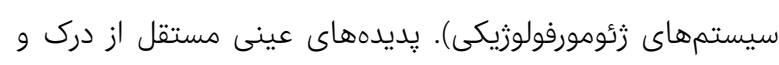

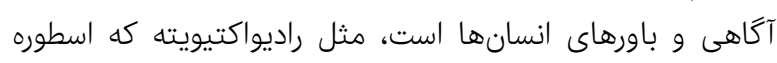

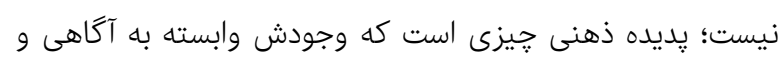

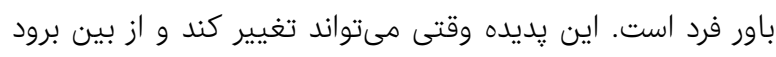

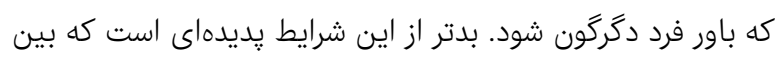

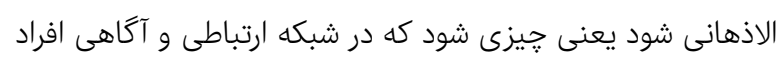

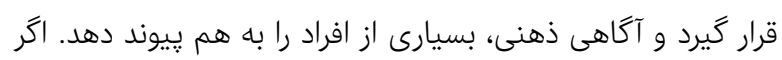

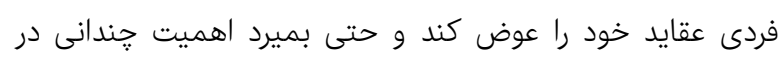

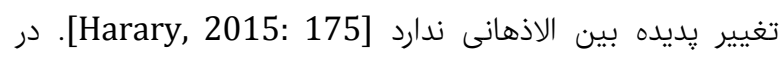

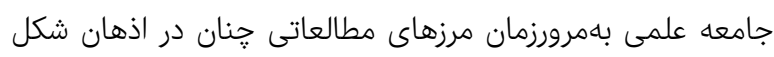

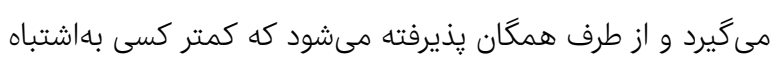

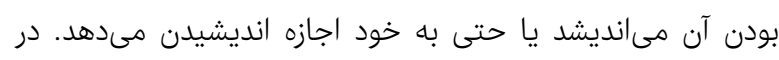

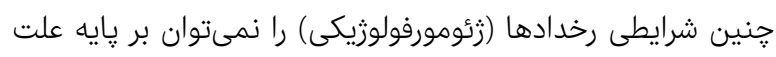

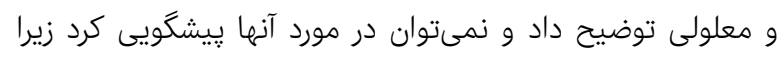

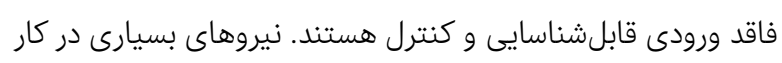

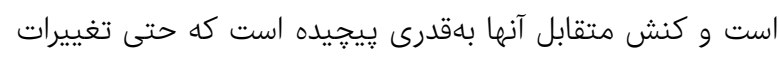

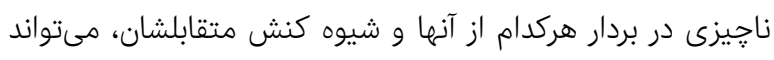

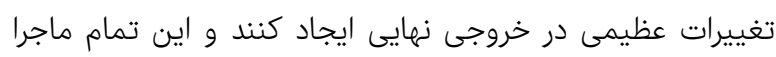

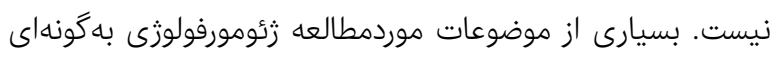

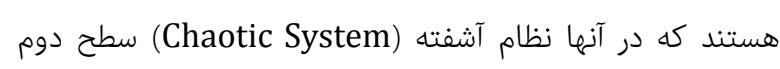

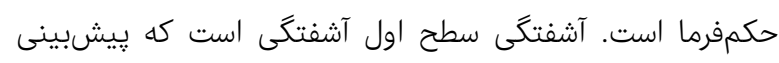

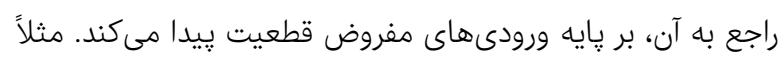

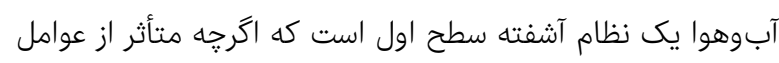

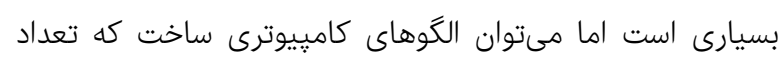

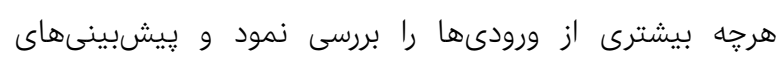

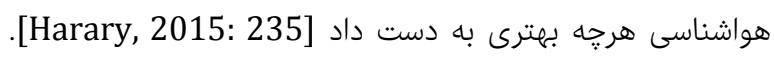

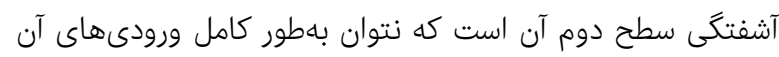

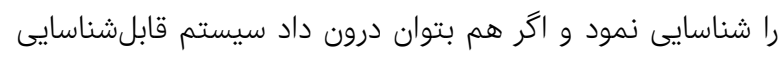

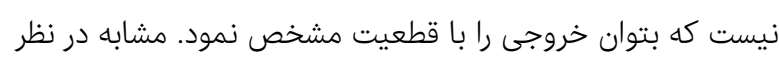

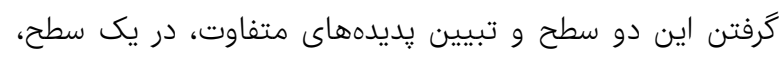

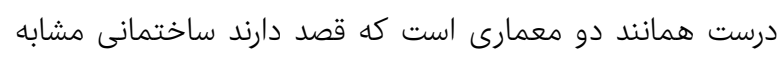

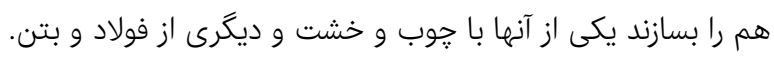

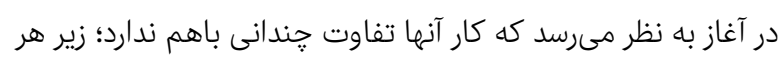

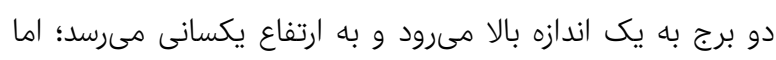

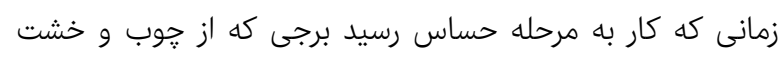

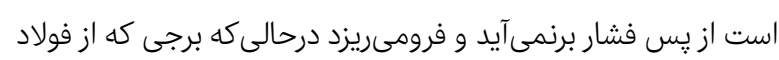

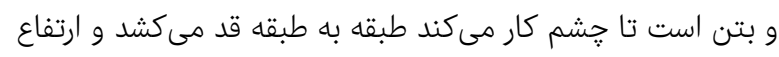

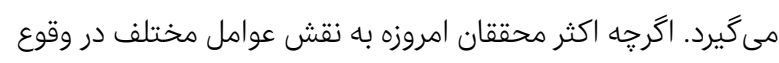

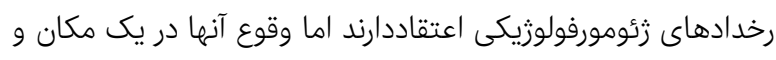

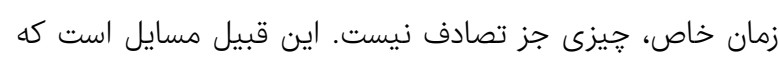

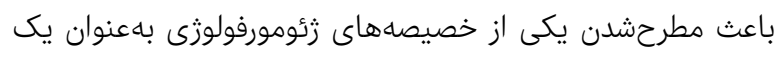

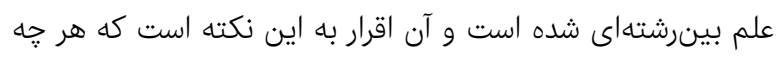


مىنمايند (فرا متنى). ازنظر زمينى نيز مرز حوضه هيدرولوزيك

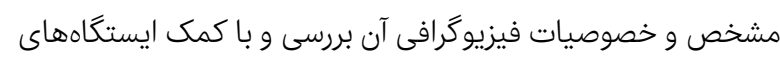

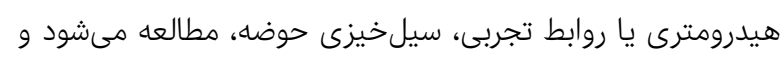

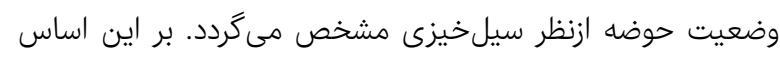

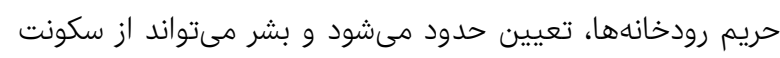

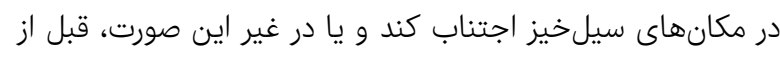

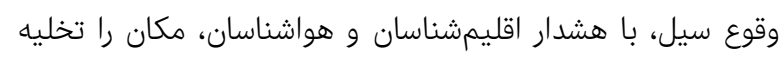

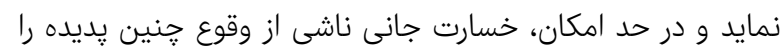

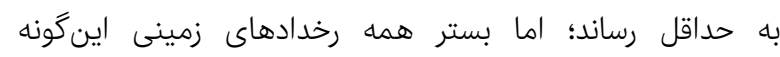

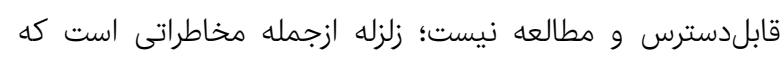

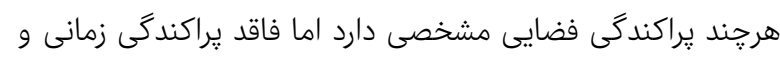

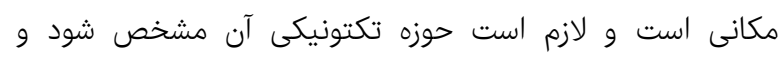

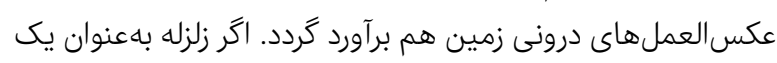

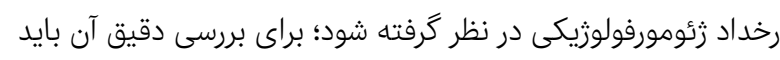

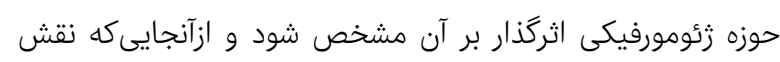

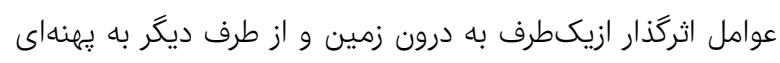

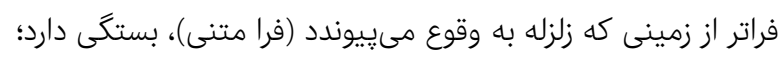

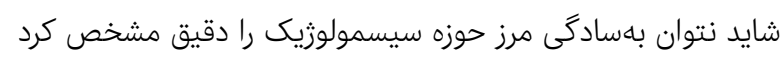

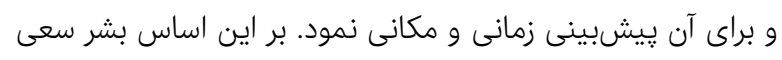

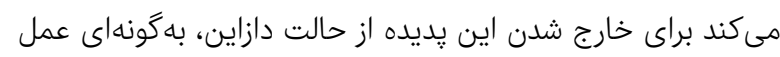

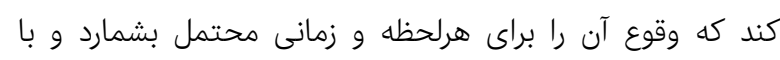

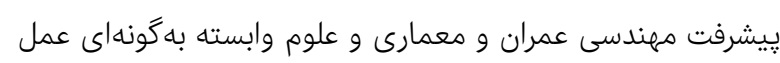

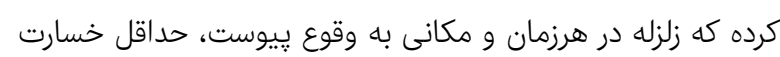
جانى و مالى را به دنبال داشته باشد. شرط لازم و ضرورى مفيد بودن تحقيقال داشته بات علمى براى باى جامعه بشرى،

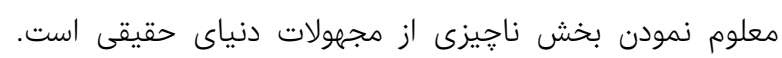

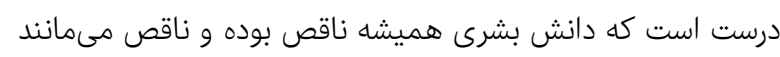

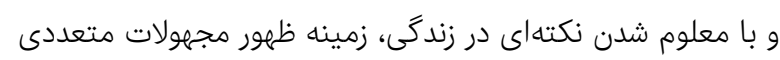

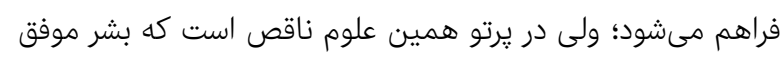

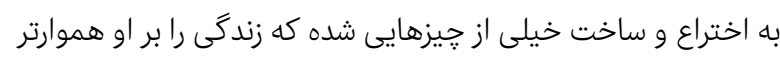

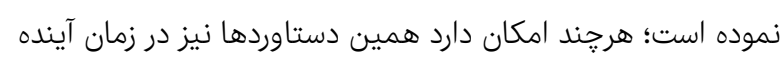

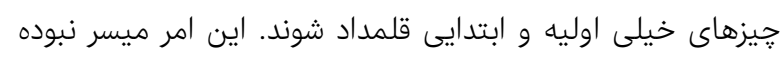

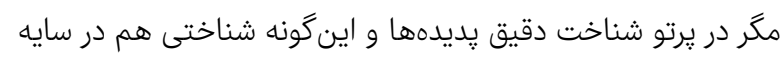

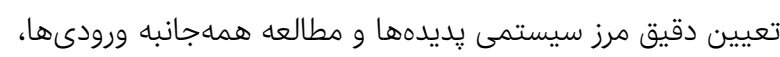

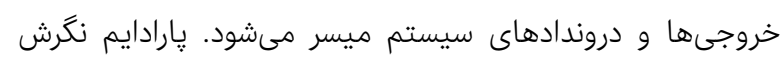

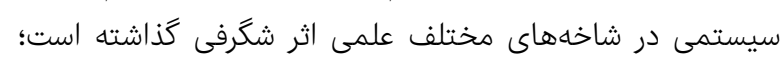

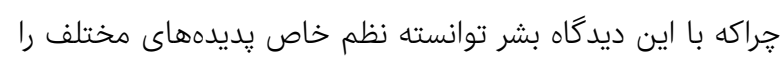

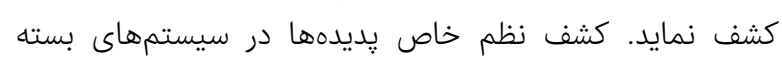

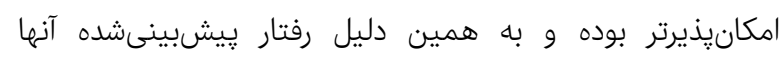

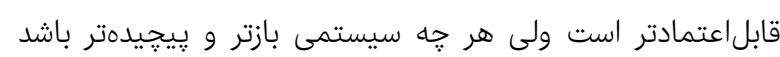

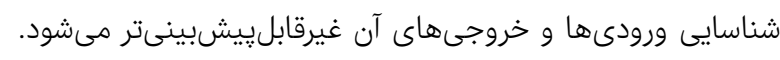

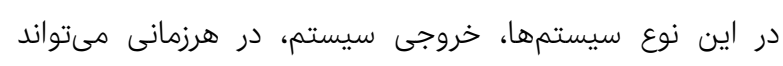

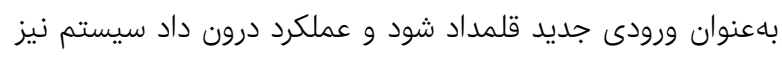

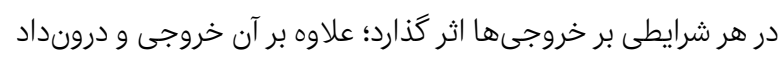

كشف نمود. كشف قوانين نظام و الكوهاى فضايى بديدارها ميسر

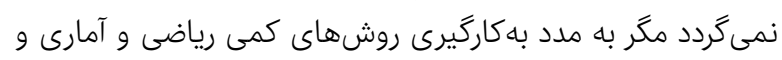

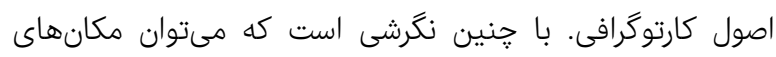

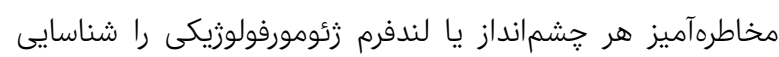

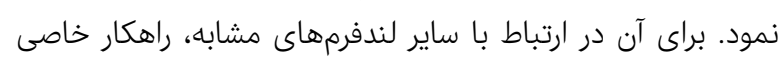

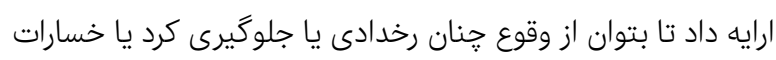

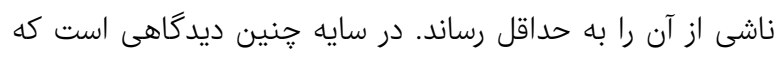

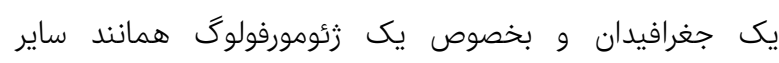

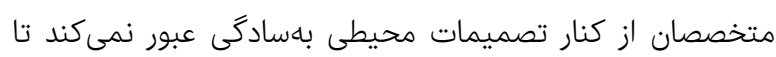

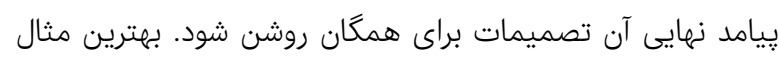

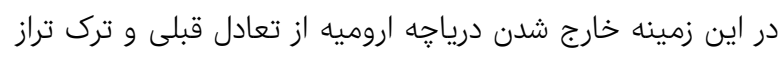

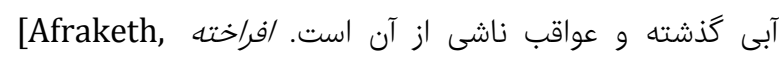

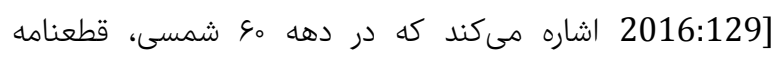

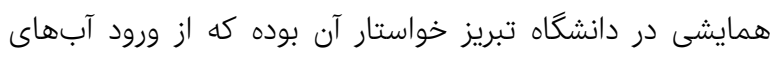

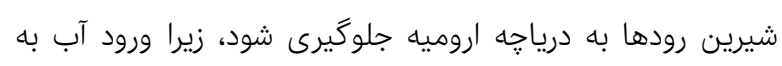

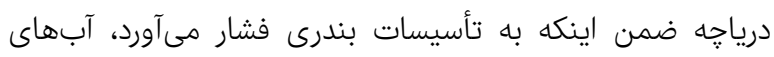

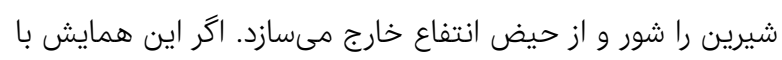

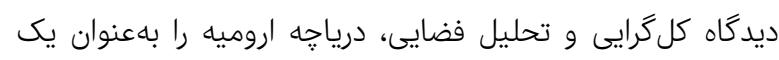

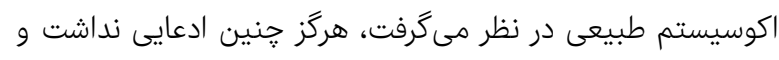

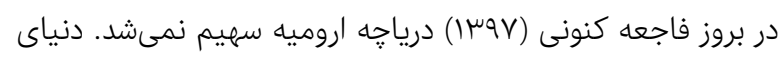

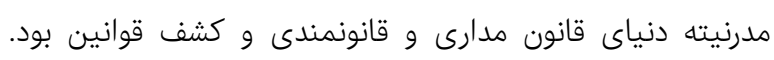

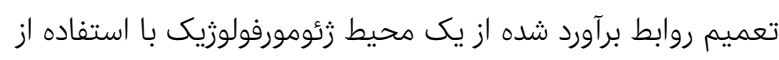

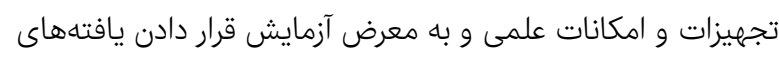

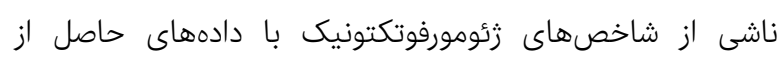

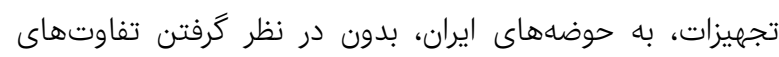

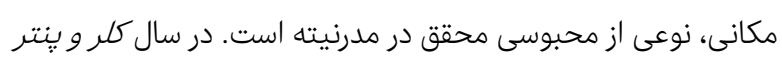

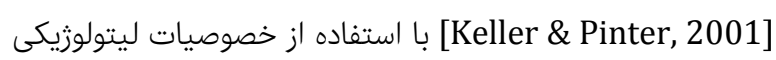

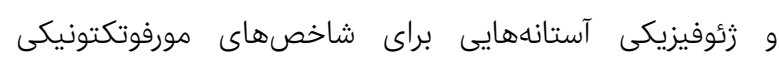

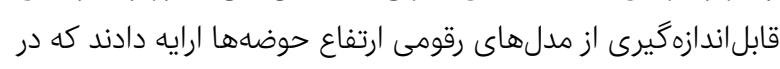

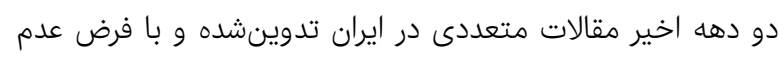

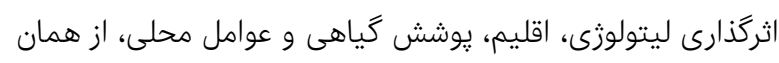

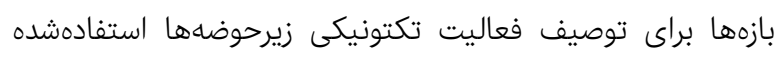

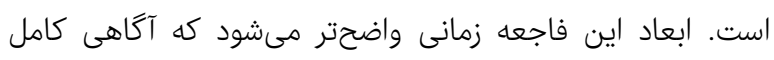

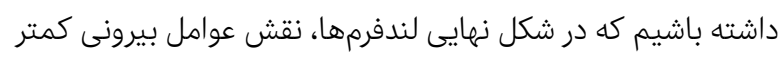

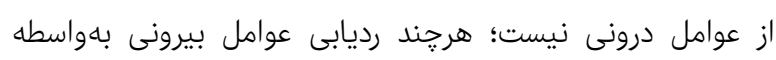

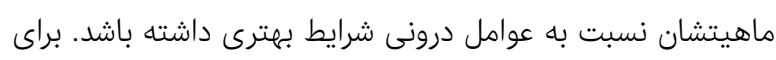

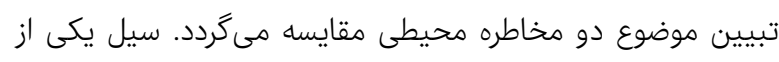

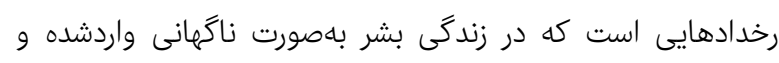

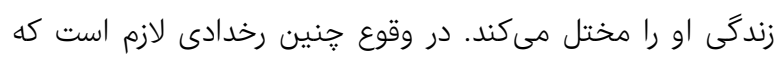

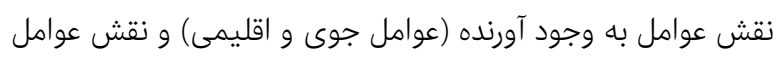

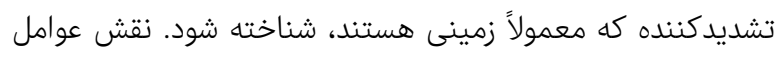

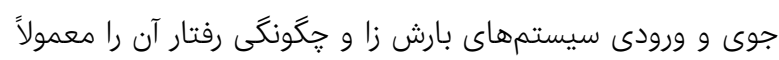

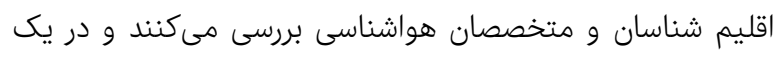

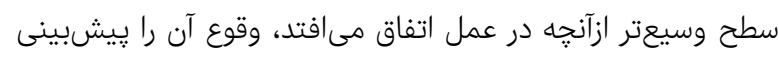


به دليل مقتضيات خاص اين گرايش از جغرافيا، محقق در اكثر موارد

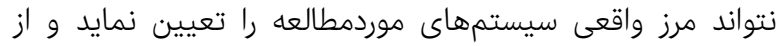
شناخت دقيق سيستم عاجز مىماند. راهحل منطقى اين مسيله

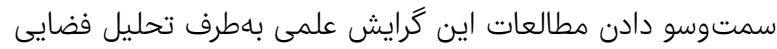

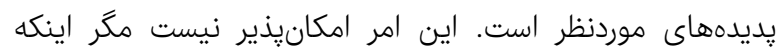

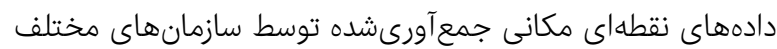
موردنياز اين علم را به دادههاى سطحى تبديل نمود (دبى، بارش،

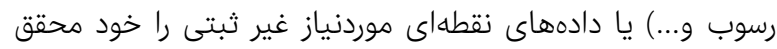

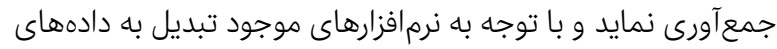
سطحى كند.

$$
\begin{aligned}
& \text { تشكر و قدردانى: موردى از سوى نويسندگًان گزارش نشده است. }
\end{aligned}
$$

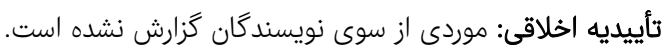

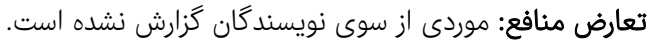

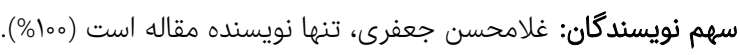

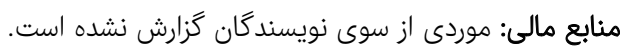

Afraketh H (2016). The transformation of geography as an interdisciplinary science. Interdisciplinary Studies in the Humanities. 8(2):119-132. [Persian]

Ahmadi M, Alijani B (2007). Spatial analysis of the role of climate on equipment and devices in Iran. Territiry. 4(13):29-42. [Persian]

Ajili H, Solgi M (2016). Critique of postmodern thought, with emphasis on the ideas of Nietzsche and Heidegger. Transformations in Human Science. 4(7):74-88. [Persian] Alijani B (2015). Spatial analysis in geography studies. Spatial analysis of environmental hazards. 2(3):1-14. [Persian]

Alijani B, Babaie-Fini A (2009). Spatial analysis of shortterm droughts of Iran. Geography and Regional Planning. 1:121-109. [Persian]

Asakereh H, Shadman H (2015). Recognition of spatial relationship of widespread hot days in Iran. Geography Research Quarterly. 30(1):53-70. [Persian]

Baas ACW (2007). Complex systems in aeolian geomorphology. Geomorphology. 91(3-4):311-331.

Bahak B (2018). Spatial analysis of dust occurrence process in Sistan and Baluchestan province using statistical methods. Geography (Regional Planning). 31(2):97-109. [Persian]

Behyar MB, Pishdad E (2016). Spatial analysis and zonation of the severity of the degree of risk of glacial events in the national road network using GIS. Nivar. 40(92-93):23-32. [Persian]

Dehbashi F, Ayatollahi HR (2009). Husserl's phenomenology is pure idealism or transcendental idealism. Philosophical Knowledge. 6(4):139-172. [Persian]

Dermot M (2000). Introduction to phenomenology. $1^{\text {st }}$ Edition. London: Routledge.

Emami Sigaroodi A, Dehghan-Nayeri N, Rahnavard Z, Nori-Saeed A (2012). Qualitative research methodology, phenomenology. Holistic Nursing and Midwifery. 22(68):56-63.

Fattahian M (2013). Changes in temporal spatial pressure on the climatic zone of Iran [Dissertation]. Zanjan: Zanjan University. [Persian]
ديكر سيستمها نيز بر رفتار سيستم موردمطالعه اثر مى گذارد. جنين

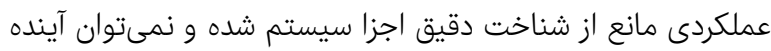

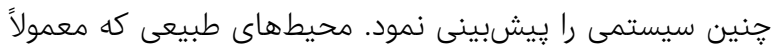

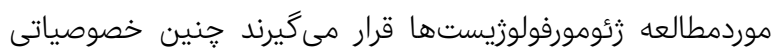

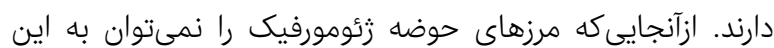

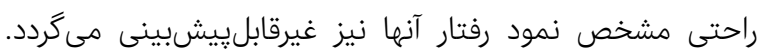

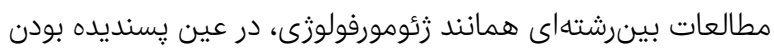

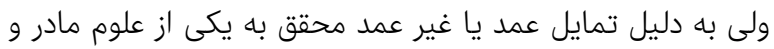

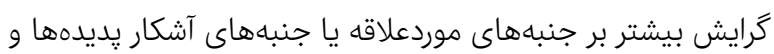

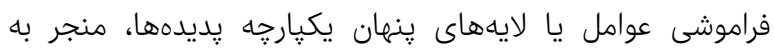

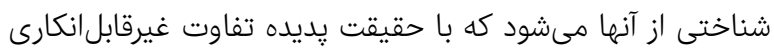

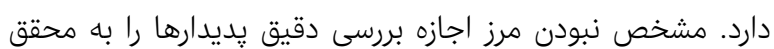

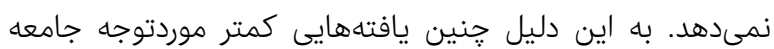

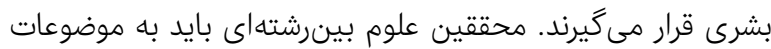

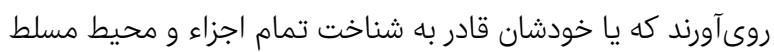

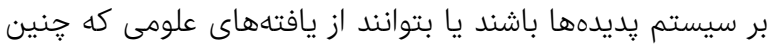

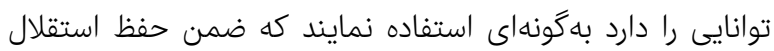

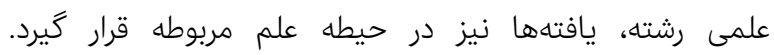

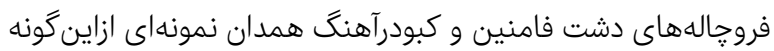

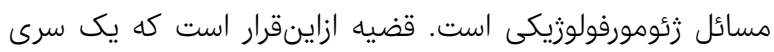

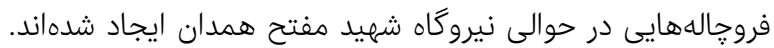

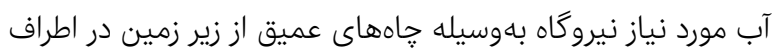

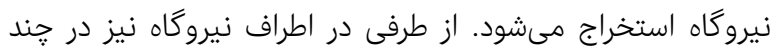

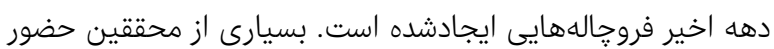

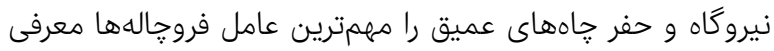

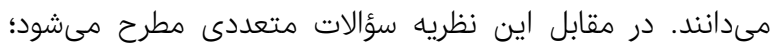

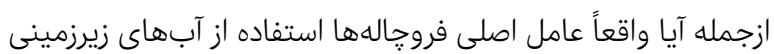

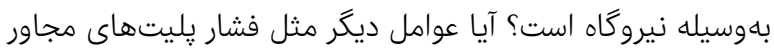

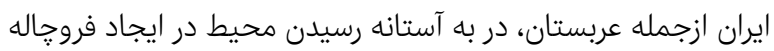

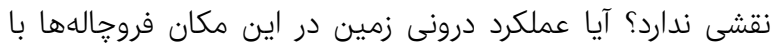

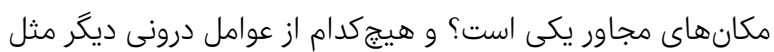

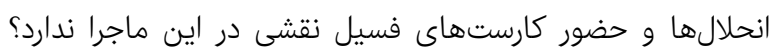

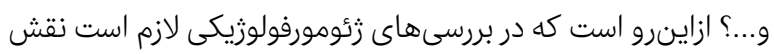

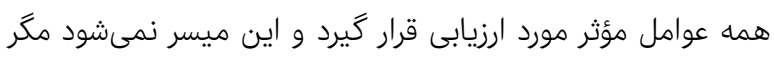

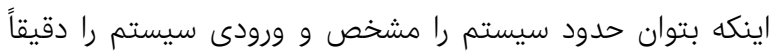

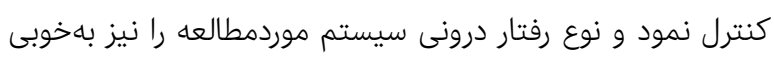

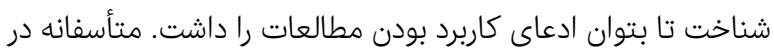

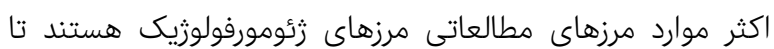

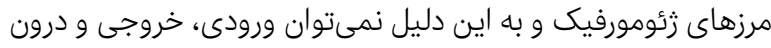
داد سيستم را كنترل نمود تا در سايه آن بتوان رفتار سيستو ييشبينى كرد.

نتيجه گيرى كاربرد نكَرش سيستمى در مطالعات زئومورفولوزيكى باعث شده كه 
Olverflet K (2015). System theory in geomorphology: Challenges, epistemological results and applied concepts. Shahbazi Ardjani R, translator. 1st Edition. Tehran: Seyedegar Publishing House. [Persian]

Parizadi T, Salehi A (2018). Spatial analysis of the factors influencing the unstable pattern of urban development (case study: Baneh city). Geographical Planning of Space. 7(26):100-114. [Persian]

Partovi P (2016). Phenomenology of the place. Tehran: Art Academy. [Persian]

Ramesht MH, Baba Jamali F, Ahmadi M (2016). Evolutionary in geographical sciences, an approaches in Nabavy epistemology Field. Geographical Researches. 31(1):4-12. [Persian]

Ramesht MH (2011). Space in geomorphology. Space Planning and Planning. 14(4):111-136. [Persian]

Ramesht MH, Mahmoudi T, Entezari M, Vali A, Rabbani A (2016). Space identity and its role in Iran civil nuclear generation. Quantitative Geomorphological Research. 4(4):56-71. [Persian]

Ramesht MH, Saffari A, Karam A, Mohammadian E (2017). Relativism in geomorphology. Physical Geography Research Quarterly. 49(1):1-20. [Persian]

Rosen N (2002). Are there different historical explanations?. Bakhshi-Pour Roodsari A, translator. Methodology of Social Sciences and Humanities. 8(33):151-168. [Persian]

Rummel RJ (1997). Death by government: Genocide and mass murder since 1900. $5^{\text {th }}$ Edition. Abingdon, UK: Routledge.

Sadeghi R, Shokryani M (2016). Spatial analysis of the development impact on internal migration -between counties- in Iran. Community Development (Rural and Urban Communities). 8(2):245-270. [Persian]

Sadeghinia A, Alijani B, Zeaiean-Firouzabadi P (2013). Analysis of spatial - semporal structure of the urban heat island in Tehran through remote sensing and geographical information system. Geography and Environmental Hazards. 1(4):1-17. [Persian]

Salimi-Bajestani H, Vojdani-Hemmat M (2015). A comparative study of the concept of death in existential psychology and the Qur'anic views of Allameh Tabataba'i. Quranic Educational Research. 6(22):7-36. [Persian] Shamaei A, Taymori S, Bahrami H (2016). Spatial analysis of population and municipal services with the approach of spatial justice Case Study: The city Khorramabad. Territory. 13(49):65-76. [Persian]

Shayan S, Maghsoudi M, Gol Alizade M, Sharifi Kiya M, Norbakhsh S (2016). Spatial analysis of aeolian landforms by fractal theory (Case study: Ardestan Rig). Physical Geography Research Quarterly. 48(2):231-245. [Persian] Shayan S, Sherifi-kia M, Zarea Gh (2011). Spatial analyses and salinity geomorphologic hazard assessment in Garmsar alluvial fan. Arid Regions Geographic Studies. 2(5):47-58. [Persian]

Sheykh Beygloo R, Taghvaeei M, Varesi H (2012). The spatial analysis of deprivation and inequalities of development in sub-provinces of Iran. Social Welfare. 12(46):215-245. [Persian]

Shokouie H (2016). New thoughts in geography philosophy. 17th Edition. Tehran: Geographical Institute. [Persian]

Sohrabifar M (2017). Heidegger and the essentiality of human being. Qabasat. 22(84):107-138. [Persian]

Taghvaei M, Kiumarsi H (2013). Spatial analysis and optimal site selection of urban parks with using GIS (Case
Ghaiumi Mohammadi H, Ramesht M, Toomanian N, Moayeri M (2009). Space and spatial view in soil and geomorphology studies. Geography and Environmental Planning. 20(3):1-20. [Persian]

Glenn Carrey J (2011). Being and human in Heidegger's Thought. Ghanbari M, translator. Kheradnameh. 3(7):107-119. [Persian]

Habibi R (2008). Introduction to the philosophy of science. Qom: Imam Khomeini Educational and Research Institute. [Persian]

Harary YN (2015). Sapiens, human history. $1^{\text {st }}$ Edition. New York: Harper Publication.

Heidegger M (2017). Being and time. Jamdi S, translator. 7th Edition. Tehran: Ghoghnos Publication. [Persian]

Hidari A (2007). The Da« (da) on "Dasein» (Dasein) book "Being and Time» (Sein und Zeit) Heidegger. Wisdom and Philosophy. 2(8):11-30. [Persian]

Hidarifar M (2013). Globalization and the transformation of the concept of geography. Scientific- Research Quarterly of Geographical Data. 21(Sepehr):77-89. [Persian]

Jahani M (2005). Chaos in atmospheric systems. Geographic Space. 4(14):137-158. [Persian]

Jamali M, Moghimi E, Jafarpour Z, Kardovani P (2015). Spatial analysis of geomorphological hazards of urban development in the banks of Khoshk river in Shiraz, Iran. Spatial Analysis of Environmental Hazards. 2(3):51-61. [Persian]

Kavianirad M (2011). Assessment of the relations between security and ecology. Geopolitics. 7(23):80-100. [Persian]

Keller EA, Pinter N (2001). Active tectonics, earthquake uplift and landscape. $2^{\text {nd }}$ Edition. New York: Pearson Publication.

Khanjar-Khani Z, Nasr-Abadi B, Ebrahimi-Dinani A (2010). Types of interdisciplinary studies in higher education. Interdisciplinary studies in humanities. 2(1):167-186. [Persian]

Lashgari-Tafreshi E (2016). Inquiry to understanding the concept of cultural geography in the school of constructivism. Arid Regions Geographic Studies 7(25):95-109. [Persian]

Lshgari-Tafreshi E, Ahmadi SA (2017). Principles of cultural geography. Tehran: Samt. [Persian]

Masoudi J (2013). Hermeneutics and religious renaissance (Edited by the Philosophy and Speech Department of Islamic Advertisements Office of Khorasan Razavi). $2^{\text {nd }}$ Edition. Tehran: Institute for Islamic Science and Culture. [Persian]

Mir-Heidar D, Hamidinia H (2006). Methodology and concepts in political geography and international relation: A comparative study. Geopolitics. 2(3):1-41. [Persian] Mir-Mosavi H, Doust-kamian M, Sotodeh F (2016). Analyzing spatial autocorrelation patterns of heavy and super heavy showers of Iran. Geography and Environmental Planning. 27(3):67-86. [Persian]

Moosavi M, Moradi H, Maleki M (2018). Spatial analysis and measurement of the status of townships of Ilam province from the aspect of having health- indicators treatment. Ilam Culture. 18(56-57):55-71. [Persian] Nawali M (1990). What is phenomenology?. Journal of Faculty of Literature and Humanities of Tabriz. (135136):96-125. [Persian]

Nietzsche F (1993). The will to the power (the will of power). Rokni M, translator. Tehran: Kultur Publication. pp. 75-37. [Persian] 


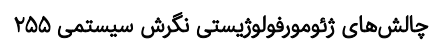

Edition. Abingdon, UK: Routledge Publication.

Yousofi A, Tabei M (2012). Empirical phenomenology, a

way to understand religious experiences. Historical

Sociology. 4(1):71-93. [Persian] study: Urban parks of Abadeh city). Geography and Environmental Planning. 24(3):55-74. [Persian]

VanManen M (2018). Researching lived experience:

Human science for an action sensitive pedagogy. $2^{\text {nd }}$ 